This item was submitted to Loughborough's Research Repository by the author.

Items in Figshare are protected by copyright, with all rights reserved, unless otherwise indicated.

\title{
An examination of the generative mechanisms of value in big data-enabled supply chain management research
}

\section{PLEASE CITE THE PUBLISHED VERSION}

https://doi.org/10.1080/00207543.2020.1832273

\section{PUBLISHER}

Taylor \& Francis

\section{VERSION}

AM (Accepted Manuscript)

\section{PUBLISHER STATEMENT}

This is an Accepted Manuscript of an article published by Taylor \& Francis in International Journal of Production Research on 2 Nov 2020, available online:

http://www.tandfonline.com/10.1080/00207543.2020.1832273.

\section{LICENCE}

CC BY-NC-ND 4.0

\section{REPOSITORY RECORD}

Meriton, Roy, Rajinder Bhandal, Gary Graham, and Anthony Brown. 2020. "An Examination of the Generative Mechanisms of Value in Big Data-enabled Supply Chain Management Research". Loughborough University. https://hdl.handle.net/2134/13026143.v1. 


\title{
An examination of the generative mechanisms of value in big data-enabled supply chain management research
}

\begin{abstract}
Big data technologies (BDT) are the latest instalments in a long line of technological disruptions credited with advancing the field of supply chain management (SCM) from a purely clerical function to a strategic necessity. Yet, despite the wave of optimism about the utility of BDT in SCM, the origins of value in a BDT-enabled supply chain are not well understood. This study examines the generative mechanisms of value creation in such a supply chain by a two-pronged approach. First, we interrogate the theoretical raisons d'être of BDT in SCM. Second, we examine the evidence that support the value-added potential of BDT in SCM informed by extant empirical and quantitative studies (EQS). Taken together, our analyses reveal three key findings. First, in extending the dynamic capabilities perspective, we deduced that micro-founded rather than macro-founded studies tend to be more instructive to practice. Second, we discovered that the generative mechanisms of value in a BDT-enabled supply chain operate at the level of supply chain processes. And thirdly, we found that resilience and agility are the most important dynamic capabilities that have emerged from current BDT-enabled SCM research. Insights for policy, practice, theory, and future research are discussed.
\end{abstract}

Keywords: big data technologies; supply chain management; systematic literature review; value creation; dynamic capabilities; generative mechanisms; microfoundations 


\section{Introduction}

Since it was coined almost a decade ago, big data has revolutionised different aspects of business processes, and supply chain management (SCM) is one of the fields where big data has shown incredible value-added potential (Chen et al., 2015a). The complex and dynamic nature of SCM (Kim et al., 2008) has made it the perfect case for big data application and it is changing the way many organisations operate (Unhelkar, 2017). Application of big data and its associated technologies has added value to SCM by contributing to its transformation from a purely clerical function to an integrated and IT-enabled one underscoring its ultimate potential as a competitive advantage to a firm. Indeed, it has been claimed that increasingly it is supply chains that compete, not companies (Christopher and Towill, 2001). The seeds of this ongoing transformation were planted at the onset of the first wave of what we now know as the digital revolution back in the 1960s with advances in information and communication technologies enabling the seamless flow of information within and between firms.

Early examples of data driven supply chains include Toyota. The company implemented its Statistical Quality Control (SQC), Just in Time (JIT) and Jidoka (automation) which together formed the Kanban production control method in the early 1960s. Employing data and information from its new Kanban methodology, Toyota began monitoring the processes of all its parts suppliers as it further developed its JIT system (Udagawa, 1995). A more recent example of how data has been leveraged to add value in a supply chain (SC) is reflected in the collaboration between Wal-Mart and PandG in the mid-1980s. Wal-Mart agreed to share its inventory positions and stock keeping unit (SKU) pricing with PandG. This allowed for errors to be quickly corrected and inventory flows optimized (Grean and Shaw, 2002). Amazon and Alibaba are two leading exponents of business models based almost entirely on data-driven SCM strategies (Folinas et al., 2004; Mahadevan, 2000). 
Data has now become 'Big Data', the amount of data available for analysis and information flows is growing exponentially. In just 10 years, the amount of cross border data has increased from 4.7 thousand of gigabits per second in 2005 to 211.3 thousand of gigabits per second in 2014 (Manyika et al., 2016), while Cisco estimates that global data centre traffic growth will triple from 2015 to 2020 . High volume and high velocity are not the only defining attributes of big data, in the original definition by McAfee and Brynjolfsson (2012) also included high variety of data from different sources as a third dimension of big data. More recently, FossoWamba et al., (2015, p. 235) stretched this original characterization by redefining big data as:

"A holistic approach to manage, process, and analyse the 5Vs (volume, velocity, variety, veracity, and value) in order to create actionable insights for sustained value delivery, measuring performance and establishing competitive advantages."

Among those $5 \mathrm{Vs}$, veracity and value, which represent the rigorousness of big data analytics (BDA), are particularly important because without data analysis, other big data processing aspects such as collection, storage, and management would not create much value (Huang et al., 2015; Chen and Zhang, 2014; Babiceanu and Seker, 2016).

Big data analytics (BDA) is the process of using analysis algorithms to uncover potentials concealed in big data, such as hidden patterns or unknown correlations (Hu et al., 2014) to facilitate data-driven decision-making (Tsai et al., 2015). According to Chae et al., (2014) BDA facilitates the realization of business objectives through reporting of data to analyse trends, creating predictive models for forecasting and optimizing business processes for enhanced performance. As such, Russom (2011) recognises that BDA is really about two things, big data and analytics and how the two have teamed up to create one of the most profound trends in business intelligence (BI) today. A multitude of terminologies are employed to describe this unification in SCM research including big data predictive analytics (BDPA) (Gunasekaran et 
al., 2017; Dubey et al., 2017), SCM predictive analytics (Schoenherr and Speier-Pero, 2015), supply chain analytics (Chae et al., 2014b), and data science (Raman et al., 2018).

In this work we adopt the more inclusive term big data technologies (Chen and Zhang, 2014) or BDT for short, to represent the various models, programs, software, and technologies that have been employed in empirical and quantitative studies (EQS) as a means to extract knowledge and intelligence from big data (Oussous et al., 2018). Empirical studies involve the direct observation of a phenomenon by following a scientific method of inquiry (Quinci, 2015) where the gathering and analysis of primary data (Soni and Kodali, 2012) are requisites. In contrast, quantitative methods include mathematical, optimisation and simulation modelling efforts (Fahimnia et al., 2015) relying mostly on secondary data input. In both approaches, knowledge creation is incumbent on the manipulation of data compared to say conceptual studies. As such, EQS can be thought of as evidence-based methodologies.

The application of BDT in supply chains has been spurred on by the continued pursuit of cost efficiencies in leading to the integration and coordination of every linkage of the chain by extensively applying a large variety of technologies, such as sensors, barcodes, RFID and IoT (Nguyen et al., 2017). This has resulted in the generation of large amounts of data across all supply chain processes. Resulting from this data explosion firms are increasingly deploying BDT in order to extract maximum value out of this ever-growing volume of data. Therefore, not surprisingly, BDT has become the latest instalment in the practice of data-driven SCM and seen by many as a competitive necessity.

Reports from industry have been used to evidence the value-added potential of BDT in SCM. For example, Baily et al., (2013) report that the application of BDT to RandD and product development has been estimated to reduce costs by $20-50 \%$, and a big data-enabled supply chain optimization was estimated as yielding a 2-3 percentage point profit margin 
improvement. Empirical evidence backs this trend demonstrating multiple advantages of BDT in SCM including improved flexibility in order fulfilment (Arya et al., 2017), increased risk management capability (Schoenherr and Speier-Pero, 2015) and enhanced opportunities for interfirm collaboration (Gunasekaran et al., 2018). Consequently, deploying a big data strategy in supply chains is increasingly being accepted as the basic unit to achieve superior firm performance and ultimately competitive advantage (Yu et al., 2018) in dynamic environments. In spite of all the hype about the potential of BDT to enhance supply chain (SC) performance, it was recently reported that only $17 \%$ of enterprises have implemented BDT in one or more SC functions (Wang et al., 2016a). It has been suggested that the main reasons for the low uptake can be attributed to the lack of understanding of how BDT can be implemented, the inability to identify suitable data (Schoenherr and Speier-Pero, 2015), limited agreement regarding the performance of big data (Addo-Tenkorang and Helo, 2016), low acceptance, routinization and assimilation of BDT by organisations and SC partners (Gunasekaran et al., 2017), and data security issues (Fawcett and Waller, 2014; Dubey et al., 2016). In other words, it can be argued that there is a lack of clarity and understanding on how BDT actually adds value to the practice of supply chain management (Matthias et al., 2017). Indeed, many scholars have cast a sceptical gaze expressing apprehensions if not throwing caution to the wind when discussing the value of BDT research to advancing SCM practice. For instance, Brinch et al., (2018) remark that many fundamental questions are yet to be addressed. According to Roden et al. (2017), these include, to what extent can big data affect processes and operating model? Furthermore, in practical terms, Richey et al. (2016) conclude that unbiased managerial guidance on the application of big data is currently weakly established.

Due to these omissions and ambiguities, Mikalef et al., (2017) note that practitioners are left in unchartered territories when faced with implementing BDT-related initiatives in their firms. This view is echoed sharply by Weiland et al., (2016) observing that researchers need to 
distinguish between the real potential, the value, and the social media marketing of the themes created by consultants and other non-academic authors. Notwithstanding, academic studies may not be completely above board when it comes to creating inappropriate sets of knowledge as there may well be a disconnect between research and real-life practice (Moody, 2000). Evidence-based practice in SCM stands to benefit from meaningful research that runs as close to reality as possible. Additionally, research works that are of greatest value to society are impactful to practice whilst fostering positive changes (Gray et al., 2015). For these reasons, research works that are operationalised in abstract terms serve little to no purpose to practitioners.

To the extent that practitioners rely on research as a guide for action, as academics we have a duty of care to examine the utility of ongoing research to practice (Wainwright et al., 2018). There is thus a need to audit the evidence-based literature (Yeh, 2005) with a view of assessing whether current research is producing appropriate sets of knowledge with the desired effect of informing practice (Musa and Dabo, 2016). To achieve this, our study offers a systematic review of the empirical and quantitative studies. Systematic reviews have become a major approach in evidence-based practice in SCM and are increasingly being used to close the research-practice gap (Hohenstein et al., 2015). Light and Pillemer (1984) explains their ability to synthesize evidence in published research, a practice that can create new knowledge and, thus, is as important as conducting new research. Our review is guided by the following questions:

1. How has BDT-enabled SCM studies been operationalised?

2. What is the nature of the evidence that support the value-added potential of BDT in SCM?

3. How has the value of BDT been captured in extant SCM studies? 
The rest of this paper is structured as follows. In the first instance we employ theoretical arguments to show that BDT has a place in the value creation conversation in SCM research. Next, we present our rigorous review methodology, and the selection and evaluation criteria for databases, journals, and articles. Then, we analyse and synthesize the literature, then present the results of our systematic review. The paper concludes with key findings, and paths for further investigation.

\section{The theoretical raison d'être for BDT in SCM}

Several theoretical perspectives have been rallied to examine the mechanics of value creation in SCM and chief among those include resource dependence theory (RDT) (Pfeffer and Salancik, 1978), stakeholder theory (e.g. Freeman, 1984), absorptive capacity (Zahra and George, 2002) and resource based view (RBV) (Barney, 1991). RBV, which attributes improvement in firm performance to differential resource endowments controlled by a firm (Barney 1991; Peteraf, 1993) has so far proven to be the most popular (Arunachalam et al., 2018) if not useful. The roots of RBV can be traced back to humble beginnings in Edith Penrose's writing. In her 1959 piece she was one of the first scholars to articulate the centrality of resources to a firm's value creation efforts. It was however Barney (1991) who formalised RBV into a comprehensive theoretical framework (Newbert, 2007). Barney argues that ultimately a firm's value lies in achieving competitive advantage over its rivals and in the short term this is derived from resources that are valuable and rare. However, sustained long term competitive advantage requires resources' inimitability and non-substitutability.

As articulated by Barney, RBV has attracted criticisms for failing to provide explanations of how and in what context resources can provide competitive advantage to a firm (Eisenhardt and Martin, 2000). Others target its static nature suggesting that resources, such as big data technologies, are not inherently valuable in and of themselves. Indeed, Yu (2015) remarks that 
implementing big data technologies in the supply chain process does not guarantee enhanced firm performance. Rather, value creation is incumbent on how resources are leveraged to create unique capabilities (Barney 1997; Teece et al., 1997). The notion of capabilities thus surfaced to address the value creation conundrum associated with resources.

Compared to resources, capabilities operate at a higher level of abstraction. Indeed, a firm's capabilities have been variously associated with higher level constructs that build on the interaction of resources (Wu et al., 2010). Grant (1991) for instance defines capabilities as what a firm can do as a result of teams of resources working together, according to Wang and Ahmed (2007), this encapsulates both explicit processes and those tacit elements embedded in the processes. Viewing capabilities as processes suggests that these are action oriented and as such it is common to speak in turns of routines in their descriptions. Emphasising the hierarchical distinction from a resource, Winter (2003) recognises a capability as a high-level routine whose socially complex nature determines the efficiency with which firms transform inputs into outputs (Collis, 1994). It has been argued that it is due to its embeddedness and socially complex nature that a capability acquires its uniqueness, idiosyncrasies and inimitability (Pandza et al., 2003), in other words its value-added potential.

In SCM studies it is now common to speak in terms of supply chain capabilities as the main conduits of value creation. These are defined by Melnyk et al., (2009, p. 3) as "the systems, processes, routines, and skills that the organization develops through its supply chain to solve specific types of problems." In the now established IT-enabled SCM literature scholars seek to examine how IT resources could be leveraged to achieve superior supply chain capabilities. For example, application of IT infrastructure in supply chains (e.g. ERP, SAP, etc.) has been shown to foster supply chain integration argued to be a higher-order process capability (Rai et al., 2006). Due to the explosion of data in recent years research emphasis has shifted to more narrowly focus on how BDT could be leveraged to create additional value in supply chains. 
Ensuing studies have thus sought to explicate the relationship between BDT and superior supply chain capabilities.

The competitive landscape is however continuously shifting spinning out losers and winners in the process. In volatile environments and dynamic competition organisational capabilities may easily invert from a strategic asset into a strategic burden (Schreyögg and Kliesch-Eberl, 2007). Leonard-Barton (1992) coined the term 'core rigidities' to refer to the attributes that can add up to a barrier of adaptation and a burden with respect to flexibility and change (Schreyögg and Kliesch-Eberl, 2007). Dynamic capabilities (DC) are required for the vagaries of modernday marketplace. These are higher order capabilities argued by many to be the building blocks of long-term, sustainable competitive advantage, particularly under conditions of uncertainty and dynamism. For instance, Teece et al., (1997, p. 516) define DC as "the ability to integrate, build and reconfigure internal and external competences to address rapidly changing environments and to achieve new and innovative forms of competitive advantage." To Eisenhardt and Martin (2000, p. 1107) these are "the organisational and strategic routines by which firms achieve new resource configurations as markets emerge, collide, split, evolve, and die." Therefore, it can be argued that under conditions of change and uncertainty the strength of capabilities no longer flows from architecture but rather from its ability to continuously produce new constellations and solutions (Schreyögg and Kliesch-Eberl, 2007). In the SCM context the principle of DC has been leveraged to theorise the role of BDT in this dynamization process. For example, Chen et al., (2015b) argue that when applied dynamically across the breadth of the supply chain, BDT create competitive advantages by extracting invaluable intelligence which can be used by decision makers to produce better resource configurations and reconfigurations leading to the creation of higher order SC dynamic capabilities.

Although the notion of dynamic capabilities was conceptualised to aid with the explication of capabilities evolution, and thus firm adaption under dynamic conditions, widespread 
acceptance of how this is achieved is lacking. Part of the problem with dynamic capabilities and indeed capabilities, lies in their characterizations as routines, albeit higher level ones. Routines are associated with stability and inertia (Feldman, 2003) and in dynamic situations routines are likely to concurrently turn valuable capacities into rigidities (Schreyögg and Kliesch-Eberl, 2007); a situation dynamic capabilities seek to prevent. Furthermore, the performance effects of DC have been a challenge to establish empirically (Drnevich and Kriauciunas, 2011). This stems from the fact that most empirical capabilities and DC studies, operationalise value creation at a macro-level. Many strategy scholars, including Barney, agree that macro-level explanations are insufficient to explain the performance heterogeneity between firms (Barney and Felin, 2013) and have called for microfoundational studies to examine how capabilities are built.

The basic motivation for the microfoundations research agenda (Foss and Pedersen, 2016) is to explicate how capabilities are created and emerge from the interaction between a firm's resources and processes (Felin and Foss, 2005). Here, emergence takes a philosophical turn in that it is essentially relational and embedded in interactions, nonetheless emergent properties, such as capabilities, are not contained in the constituents themselves but could not exist apart from them (Archer, 1982). In other words, capabilities exemplify a micro-macro emergence (Easton et al., 2012) and as such possess unique properties that are irreducible to their parts. As discussed above, capabilities are also the conduit of value in supply chains. The characterization of supply chain capabilities as emergent would be in keeping with the view of SCM as a set of management processes (Mentzer et al., 2001). This is because, in this school of thought the concept of supply chain management is defined as "the integration of key business processes from end user through original suppliers that provides products, services and information that add value for customers and other stakeholders" (Lambert and Cooper, 2000, p. 66). Given that capabilities are action oriented (Meriton and Pandza, 2015) it is thus 
through the execution of these key business processes that supply chain capabilities emerge. Therefore, microfoundational studies in BDT-enabled SCM would examine how supply chain capabilities are created and emerge from the interaction between big data technologies and key supply chain business processes. It is our contention that these would provide appropriate sets of knowledge to practitioners wishing to leverage BDT in their day-to-day operations in order to achieve performance gains.

\section{Methodology and initial data statistics}

Several systematic literature reviews (SLR) addressing BDT applications in SCM have been produced, however the majority tend to combine conceptual and non-conceptual studies in the analysis. For example, Barbosa et al., (2018) seek to examine the resources managed by BDT as well as the SCM processes involved by conducting a systematic literature review, yet 15 out of the 44 articles retained for analysis are conceptual in nature. Our review is unique as it surveys only evidence-based literature.

A systematic literature review differs from a traditional narrative review in that it adopts a replicable, scientific and transparent process (Barbosa et al., 2018). Tranfield et al. (2003) put up a strong defence in support of SLR as a prime contender of an evidence-based approach. They are of the strong view that by synthesizing research in a systematic, transparent, and reproducible manner a SLR is widely regarded as providing high-quality evidence. Thus, whilst the reviewing process increases methodological rigour for the academics, for practitioners it helps develop a reliable knowledge base by accumulating knowledge from a range of studies. Therefore, it is our contention that a SLR for synthesizing prior evidence-based research on $\mathrm{BDT}$ in $\mathrm{SCM}$ is an appropriate methodology that can be used to inform practice.

Systematic literature reviews follow a number of key steps, which include defining appropriate search keywords, searching the literature and completing the analysis (Saunders et al., 2007). 
The methods for conducting systematic reviews are different from traditional literature reviews because they have been developed to minimize the effect of selection, publication and data extraction bias (Nightingale, 2009). Rowley and Slack (2004) document a structured methodology involving evaluating the information sources, searching and locating information resources, developing the conceptual frameworks and mind mapping and writing the literature review. In a similar vein and drawing inspirations from previous systematic reviews related to SCM, such as Fahimia et al., (2015), we use a four-step methodology for data collection and comprehensive evaluation of BDT in SCM empirical and quantitative research to identify the actual value-added potential of BDT to SCM.

\subsection{Defining the search terms}

We drew inspiration from previous literature reviews for the initial ideas for the keywords. Several pilot searches were then performed to refine the keywords in the search string using trial and error (Saltz and Shamshurin, 2016). The terms whose inclusion did not yield additional papers in the automatic searches were removed. A team composed of three academics and two experienced supply chain managers was then composed to carefully examine the phrases to give the search terms a sound validity in relation to the review questions. This process resulted in the formulation of a two-level key-word structure with the intent of catering for a broad range of search terms for capturing published works at the intersection of SCM and BDT. In Table 1 the final assembly structure is illustrated where level one defines the search context (supply chain) and level two shows the related BDT keywords. The Boolean operator "OR" is used to link keywords within levels whereas "AND" is used to connect the two levels.

\subsection{Initial search results}

Using the search string shown in Table 1 we searched for articles in the 'title, keywords and abstract' field in Scopus. Scopus is now considered the largest searchable citation and abstract 
source of searching literature which is continually expanded and updated (Rew, 2010). However, one of the arguments against Scopus is that compared to Web of Science, its coverage is limited to recent articles (Aghaei et al., 2013). Given that BDT in SCM is a fairly nascent research field we did not see that limitation as injurious to our study. Recent reviews employing Scopus as the main resource for data collection include Lamba and Singh (2017) and Gupta et al., (2017). The search was limited to include articles published up to and $31^{\text {st }}$ December 2019. The initial search yielded 1400 articles which were subjected to further screening to ensure their suitability for the study. The following criteria, based on Newbert (2007), were considered to include/exclude papers:

- Included papers published in peer-reviewed academic journals in English.

- Selected articles contain at least one keyword in their title, abstract or keyword.

- Only papers presenting empirical evidence and quantitative modelling were retained.

- Ensure substantive and empirical relevance by reading all remaining abstracts.

- Further ensure substantive and empirical relevance by reading all remaining articles in their entirety.

Table 1 also illustrates the steps involved in locating the relevant articles for the study. A final sample of 83 articles was judged to meet our selection criteria and was retained for further analysis.

[Insert Table 1 near here]

\subsection{Initial statistics}

In Table 2 the distribution of articles by year of publication is presented. Although the term 'big data' was coined by "Gartner Inc." in 2007 (Verma and Pandey, 2018) and researching the phenomenon began in earnest in 2012 (Fosso-Wamba et al., 2012), the empirical and quantitative literature seems to have lagged behind. The earliest works in our sample date back 
to only 2014. Since then, there has been a gradual uptake in publication peaking in 2018 with 26 studies.

[Insert Table 2 near here]

The distribution of publications by journal is found in Table 3. The table shows a diverse outlet for such studies. Whilst most of the journals in the list can be classed as 'operations and supply chain' oriented, a few falls outside this description. For example, Technological Forecasting and Social Change is classed as an innovation journal by the most recent journal quality list (Mingers and Harzing, 2007) whereas the Journal of Management Information Systems falls within the management information system and knowledge management subject area. These observations suggest a wide and diverse audience and outlets for studies examining this knowledge intersection. Table 3 also shows that most of the journals included in the sample are ranked ABS 3 (Harvey et al., 2010) or better with two of the journals, Journal of Management Information Systems and Production and Operations Management achieving a 4* ranking indicating world elite quality. In terms of prominent outlets, The International Journal of Production Research (IJPR) is recognised as a leading name in moving the field forward publishing more quality articles $(\mathrm{f}=13)$ than its contemporaries.

[Insert Table 3 near here]

Table 4 shows the distribution of publications by country for the first or corresponding authors. The figures in the table suggest that $59 \%$ of all the publications are shared between only four nations with United States (18\%) having the lion share of the spoils followed by United Kingdom (UK) (16\%), India (11\%), and China (10\%). There is however a good balance of representation between developed countries and emerging nations although representations from African countries are notably missing. 
[Insert Table 4 near here]

\subsection{Content Analysis}

In order to penetrate the literature and conduct a more fine-grained analysis we relied on the traditional content analysis technique. Content analysis is praised for its ability to systematically evaluate the symbolic content of all forms of recorded communication (ValletBellmunt et al., 2011). It achieves this by codifying qualitative and quantitative information into pre-defined categories in order to extract patterns in the presentation and reporting of information (Guthrie and Abeysekera, 2006). According to Kolbe and Burnett (1991) its main advantages include its sensitivity to the context from which information is obtained, it is unobtrusive, and it provides an empirical starting point for generating new research.

Content analysis has been applied to illuminate various aspects of SCM research. For example, Stock and Boyer (2009) deploy a content analysis on previously published SCM definitions to develop a consensus definition of SCM. Seuring and Muller (2008) for their part employ a content analysis to develop a conceptual framework that summarises research in the area of sustainable SCM. In this work a content analysis is used to illuminate how big data technologies create value for supply chain management. Guthrie and Mathews (1985) argue that for content analysis to be effective the categories of classification must be clearly and operationally defined.

The analysis template was developed during a brainstorming session involving all the authors, in line with the research questions it was agreed that the following themes should be captured during the initial coding exercise:

1. Methodology and studies' operationalization

2. Source of big data employed in the studies

3. Host industry for BDT-SCM research

4. Value created by BDT in SC 

a. BDT-enabled processes
b. BDT-enabled SC performances

To achieve reliability, we followed recommendations from notable authorities such as Gold and Seuring (2011). Two authors performed the analysis independently. Given that the analysis template was developed a priori, deductive thematic analysis was employed to carefully examine the 83 articles and to extract the relevant information which was recorded in a table. The two authors presented their findings in a progress meeting; small discrepancies were addressed through dialogue. The outcome of this meeting was a fully populated and validated content analysis framework which provided a dataset for further analysis and interpretation in the sections that follow.

\section{Findings}

\subsection{Dominant methodologies}

The empirical and quantitative sample represents a broad spectrum of methodological approaches. Table 5 lists the dominant approaches and the frequency they are employed, and these include survey, case study, modelling, and big data architecture. The most dominant type of study is survey ( $\mathrm{f}=28, \mathrm{P}=35 \%$ ) followed by modelling ( $\mathrm{f}=27, \mathrm{P}=32 \%$ ), architecture ( $\mathrm{f}$ $=19, \mathrm{P}=23 \%)$, case study $(\mathrm{f}=7, \mathrm{P}=8 \%)$ with mixed-methodology $(\mathrm{f}=2, \mathrm{P}=2 \%)$ the least popular. Modelling methodologies mainly involve solving a supply chain problem by employing different types of mathematical algorithms. In most cases a case study is used to validate the model developed. For example, Kahi et al., (2017) proposed a data envelopment analysis (DEA) model to evaluate sustainable supply chains in which networks have a series structure. Supply chain operations data from an Iranian food production company constitute the input to assess the applicability and validity of the model. 
Big Data architecture approach is distinguished from modelling in that it involves the design and validation of a big data analysis protocol constituting data mining, data analytics and visualisation. Examples of the architecture approach include Tan et al., (2015) and Giannakis and Louis (2016). In Tan et al., (2015) the authors developed and tested an analytic infrastructure based on the deduction graph technique. To validate the proposed architecture the authors employed both structured and unstructured data from the case company's data warehouse and customer reviews respectively. The architecture developed by Giannakis and Louis (2016) is a multi-agent-based SCM system that incorporates big data analytics. Data generated from four scenarios using scenario planning is employed to test the system. One of the key strengths of architecture over modelling is the ability of the former to handle different types of big data. Whilst modelling appears to be best suited for structured quantitative data, the architectures developed by the authors in our sample can process structured and unstructured data in both quantitative and qualitative formats. Furthermore, the integration of analytics in the architectural frameworks is amenable to the production of visual outputs that can be readily understood compared to those resulting from modelling.

[Insert Table 5 near here]

Survey-based works are all cross-sectional in nature employing different analytical techniques. Structural equation modelling (e.g., Chae et al., 2014a; Chavez et al., 2017; Dubey et al., 2017) is the analytical technique of choice, other statistical tests employed include Delphi-based analytic hierarchy process (AHP) (Moktadir et al., 2018), descriptive statistics (Sanders, 2016), multiple regression analysis (Gunasekaran et al., 2017) and Fuzzy c-means clustering (Roßmann et al., 2018). Most studies rely almost exclusively on primary data collected through questionnaires, however, a few combined primary with secondary data as in the case of van de Spoel et al., (2017) where survey data is coupled with GIS traffic and weather data as well as in Papadopoulos et al., (2017) where survey data is complemented with social media data. 
Nevertheless, in these studies the survey data take precedence in terms of testing for relationships. Only one study by Chae et al., (2014b) relied exclusively on secondary data from a large-scale survey by a third party. The sample also comprises seven case studies. Four multiple cases by Gunasekaran et al., (2018), Kumar et al., (2016), Prasad et al., (2016) and Zaki et al. (2019), two single cases by Andersson and Jonsson (2018) and Zhan et al., (2016) and a secondary case study by Choi et al. (2018) populate this group. Apart from Prasad et al., (2016), where the cases are taken from humanitarian value streams, all the other studies involve one or more manufacturing firms. Furthermore, as observed with the survey methodology, most of the cases are cross-sectional with Zhan et al., (2016) the only exception. Two mixed-method studies by Ellis et al. (2018) and Brinch et al. (2018) complete the methodological line-up.

Finally, we examined the distribution of methodology across the three continents, Table 6 summarizes our findings. The findings show that authors from the America favour survey methodology $(f=10)$ over other approaches. In contrast, authors from Asia tend to rely on mostly modelling $(f=18)$ and architecture $(f=9)$ and to a lesser extent on survey $(f=7)$. Europe displays a more balanced picture survey $(\mathrm{f}=11)$ being the most dominant approach followed by architecture ( $f=7$ ), modelling $(f=6$ ) and case study ( $f=4)$. Perhaps these differences are a reflection on the nature of the skills-set across the different continents with authors from Europe showing a more rounded and balanced profile compared to authors from Asia and America. Authors from the latter two continents show a greater aptitude for quantitatively driven methodologies.

[Insert Table 6 near here]

\subsection{Studies' operationalisation}

We interrogated the articles to establish the ways in which studies had been operationalized. Ten different permutations of operationalising big data technologies were identified which we 
grouped under two broad headings, macro-level and micro-level. Studies are clustered according to these permutations and shown in Table 7. Macro-founded studies $(f=24)$ are those that treat big data technologies as functional wholes (Ekström, and Selviaridis, 2014). These are capabilities that operate at the supply chain level and studies mostly adopt a survey methodology where the big data technology is measured as a multi-item scale. Several terminologies are employed, including big data predictive analytics capability and supply chain analytics. Table 8 captures the whole nomenclature employed in macro-founded studies to describe big data technologies in their capacity as a supply chain capability showing that most studies employed the term big data analytics capabilities (BDAC).

[Insert Table 7 near here]

[Insert Table 8 near here]

Macro-founded studies have conceptualised big data analytics capabilities (BDACs) in three ways which we coded C-C (capability-to-capability), C-P (capability-to-performance) and CC-P (capability-to-capability-to-performance). Consequently, the effects of BDACs of the macro-founded studies are felt at the operations or firm level. Studies in group $\mathrm{C}-\mathrm{C}(\mathrm{f}=5)$ examined the direct impact of BDA capabilities on supply chain capabilities. For example, Sanders (2016) found that leveraging BDA in supply chains has the potential to improve a firm's capability for inventory optimisation and supplier negotiation amongst others. In group C-P $(f=12)$ includes studies that examined directly the performance impact of BDACs in supply chains. Example include Chae et al. (2014a) who found that fact-based supply chain management moderated the impact of advanced analytics on operations performance. A variant of C-C, studies in group C-C-P ( $\mathrm{f}=7)$ involved an additional level of complexity dealing with two levels of capability and one of performance. For example, in Fernando et al. (2018), the 
authors showed that supply chain innovation capabilities mediated the relationship between big data analytics and service supply chain performance.

Most studies in our sample are micro-founded $(\mathrm{f}=59)$ as they treat big data as the input resources that are transformed into capabilities by employing a variety of analytical and modelling techniques. These analytical procedures work to extract important intelligence from a big data set that can be leveraged into enhanced predictive or prescriptive capabilities. These micro-founded studies also comprise most of the qualitative studies. We use the notation $R_{t}$ to denote the transformation of the input big data resources and as such labelled the three dominant subgroups of micro-founded studies as follows: $\mathrm{R}_{\mathrm{t}} \mathrm{C}$ (transformed resources-tocapabilities), $\mathrm{R}_{\mathrm{t}} \mathrm{C}-\mathrm{P}$ (transformed resources-to-capability-to-performance) and R-C (resourceto-capability). subgroup $\mathrm{R}-\mathrm{C}$ is distinguished from $\mathrm{R}_{\mathrm{t}} \mathrm{C}$ in that the former do not involve the transformation of input resources through mathematical manipulations, rather, they rely on qualitative enquiries, nevertheless the basic unit of analysis is the big data resource.

Whilst the capability effects of BDT of macro-founded studies have been shown to operate at the operations and firm level, those of micro-founded studies tend to be felt at the functional or processes level. $\mathrm{R}_{\mathrm{t}} \mathrm{C}(\mathrm{f}=34)$ is the largest subgroup of the micro-founded classification. An example of such is provided by Chen and Chien (2018). In this study the authors developed a predictive model based on a technology diffusion model. The subgroup labelled $\mathrm{R}_{\mathrm{t}} \mathrm{C}-\mathrm{P}$ ( $\mathrm{f}=$ 14) is the second largest, an example is provided by Hoffman (2017) in a dynamics modelling approach combined with the simulation of big data on three levers of velocity, volume, and variety. The subgroup $\mathrm{R}-\mathrm{C}(\mathrm{f}=6)$ mostly comprises qualitative studies which typically seek to illuminate the value of big data by employing various interpretive approaches. Through a single case study employing a mixture of in depth and semi-structured interviews, Andersson and Jonsson (2018) found that by leveraging product-in-use data European manufacturers of heavy vehicle aftermarket spare parts can improve their capabilities for demand planning and 
forecasting. A full list of improved processes emanated largely from micro-founded studies can be found in Table 12 .

\subsection{Source of big data}

Big data employed were of both the structured and unstructured type and varied in terms of origin. Table 9 presents the result of our analysis in terms of the origin of big data. According to our findings, three main sources are responsible for the big data in our sample and these have been coded as operational data $(f=23, P=37 \%)$, social media data $(f=20, P=32 \%)$, and simulated data $(\mathrm{f}=10, \mathrm{P}=16 \%)$. The categorizations in Table 10 are further broken down into subgroups. The most popular source of big data in operations are cost-related $(f=4)$ and company databases $(f=4)$. The most popular social media source is online reviews $(f=7)$ followed by twitter $(f=5)$. Whilst most authors extracted data from one source, Papadopoulos et al., (2017) stand out for mining data from several social media platforms such as Facebook, Instagram and YouTube.

[Insert Table 9 near here]

\subsection{Industries attracting BDT-SCM research}

Our analysis of the influence of big data in industries yielded some interesting insights. Table 10 lists the industries and subsectors that have attracted research interests showing that research spans different industries and economic sectors. Almost half of all the studies involved a manufacturing company $(\mathrm{f}=37, \mathrm{P}=45 \%)$. Some studies involved companies or datasets from multiple industries, we have coded this group various $(f=14)$ while in a few instances the source of the data is not specified $(f=7)$. Within group analysis revealed a strong contingent of studies within the manufacturing sample involving more than one type of manufacturing activities in one study; this is the single largest subgroup of manufacturing $(f=15)$. Single site studies show a preference for computer and electronic $(\mathrm{f}=4)$ and automobile and spare parts 
$(f=3)$. Within retailing food is the most dominant subgroup $(f=7)$ followed by e-commerce $(f=4)$. This makes food the most important subgroup overall in the context of single-site studies. BDT research in SCM is not restricted to the commercial sector; our findings reveal that BDT has also been studied in local authority $(\mathrm{f}=1)$ as well as in humanitarian value streams $(f=1)$.

[Insert Table 10 near here]

We also analysed the interaction between methodological characteristics of the sample and the dominant industries by conducting a simple crosstab analysis. The findings of this analysis are presented in Table 11. These reveal that studies involving manufacturing companies employed a mixture of primary and secondary data. The main source of big data in manufacturing is operations $(\mathrm{f}=13)$. Studies conducted in retailing have employed secondary data almost exclusively $(f=15)$ suggesting modelling and architecture as the dominant approaches. The group various $(\mathrm{f}=14)$ attracted mostly primary data $(\mathrm{f}=12)$. Studies in the group labelled "Not specified" have relied predominantly on simulated data $(f=7)$. In general, these findings appear to suggest that authors have found big data generated from operations as being more illuminating for manufacturing processes whereas retailing seem to be informed in equal measures from big data available in the public domain as well as from ongoing operations.

[Insert Table 11 near here]

\subsection{Location of value creation in a BDT-enabled SC}

As we have argued in the literature review and as we have shown in Table 7, value in a BDTenabled supply chain is captured at two different levels. Generally speaking, in micro-founded studies, value is created at the functional or process level whereas in the macro-founded studies 
value is created at the operations or firm level. We discuss these value-creation mechanisms further below.

\section{a. BDT-enabled processes - Micro-level value generative mechanisms}

The micro-founded studies are responsible for most of the BDT-enabled SC processes. We employed the Global Supply Chain Forum (GSCF) model as an overarching organizing framework to record our findings. In addition to the Supply Chain Operations Reference (SCOR) model developed by the Supply Chain Council (www.supply-chain.org), the GSCF model is considered as one of the most widely used approaches by many supply chain practitioners Lambert and Cooper (2000). The SCOR model outlines four domains of supply chain activities: source, make, deliver, and return, all of which depend on planning, a fifth domain of the SCOR model, for their effective execution (Souza, 2014). Compared to the SCOR, the GSCF is micro-founded as it focuses on business processes that link the supply chain and on depicting the physical flow of goods among members of a supply chain (Ellram et al., 2004). Further, while the SCOR framework considers only a few functional units to take charge for classifying BDT applications in SCM, the GCSR model, with an emphasis on interaction between eight business processes and cross-functional teams, is seen as a more comprehensive and efficient way Lambert and Cooper (2000). The eight key business processes of GCSR model are: customer relationship management, customer service management, demand management, order fulfilment, manufacturing flow management, supplier relationship management, product development and commercialization and return management (Cooper et al., 1997).

Guided by the GSCF we initially identified 47 sub-processes; these were then clustered at a higher order of aggregation reflecting the functional SC domains they belong to. Three authors independently aggregated the sub-processes into higher order processes. There were minor 
discrepancies between the coders; these were resolved during a brainstorming exercise which also included the participation of some practitioners from the industry. A final list comprising of six higher order SC processes of demand management, order fulfilment, product management, production management, supplier relationship management, and customer services management resulted from this brainstorming and consulting exercise. Table 12 lists the processes and their corresponding sub-processes.

The frequency (f) of the sub-processes represents the number of articles in which they have been studied with some articles investigating more than one. The frequency of occurrences of these sub-processes represents the importance given to them by researchers. Table 12 shows that demand management $(\mathrm{f}=34)$ has attracted more research attention followed by order fulfilment $(\mathrm{f}=17)$. Production management $(\mathrm{f}=11)$ and product management $(\mathrm{f}=11)$ have received the least research attention. At the level of the strategic sub-processes, demand forecasting $(f=12)$, supplier selection $(f=7)$, and market intelligence $(f=6)$ are the top three most studied in the sample.

[Insert Table 12 near here]

\section{b. BDT-enabled SC performances - Macro-level value creation}

Although most studies in our sample allude to potential value outcomes of a BDT intervention at the macro-level, only about half are backed with evidence. We observed that macro-level performance implications of BDT have been analysed at two levels, operations and the firm. To distinguish between operations and firm level value we relied partly on the information supplied by authors and partly on our collective experience as educators of SCM. Most authors were explicit in positioning where the value creation was taking place often employing the terms operations performance and/or firm performance. Furthermore, the majority of authors use a combination of the widely accepted operations performance metrics of cost, quality, 
dependability, flexibility and speed (Slack et al., 2004) in operationalising operations level value. The macro-level BDT-enabled value outcomes extracted are listed in Table 13 showing that operations outcomes $(f=64)$ greatly outnumber firm level outcomes $(f=18)$.

[Insert Table 13 near here]

\section{Discussion}

Current research suggests that value in a BDT-enabled SC is emergent, multi-faceted, and nested, and its generative dance takes place at the level of SC processes and sub-processes. Figure 1 provides an overall summary of our findings showing a potential value framework for BDT-enabled SCM. It shows that evidence-based BDT-enabled SCM studies have been conceptualised as either macro or micro. This is the most important distinction in terms of value creation, and it is illustrated in the topmost part of the value framework in Figure 1. In macrolevel studies, the value creation process is conceived as taking place at the SC or firm level. The majority of the empirical work in this literature has been operationalised at the macro-level often employing self-reported questionnaires where BDT is operationalised as a functional whole measured by means of a multi-item scale, in Figure 1 this is labelled as big data supply chain capabilities. The problem with these macro-level characterisations of value creation is that they do not provide guidance as to how the input big data resources or capabilities work to create valuable outputs.

[Insert Figure 1 near here]

Exceptions are few in the empirical literature, notable among those include a study by Gunasekaran et al., (2018). This study adopts a qualitative methodology and thus according to our categorisation, micro-founded. The crucial difference between survey-based studies and the qualitative approaches is not methodological per se, although the choice of methods does influence the granularity of the analysis. Rather, the level of operationalisation is the critical 
variance between the two sets of studies. In the survey-based research, the process of value creation is described at the supply chain or firm level, whereas in the qualitative as well as the modelling-based studies, value creation is discussed at the level of the supply chain processes, in other words at the micro-level. In modelling-based studies the units of analysis are the functional supply chain processes, algorithms are applied to big data sets to generate intelligence.

Collectively, we have called the big data sources, algorithms and supply chain processes (and sub-processes) the generative mechanisms of value. This is because, the intelligence produced by the application of algorithms to big data sets can be used as decision prompts to optimise the supply chain processes. In return, optimised processes can result in what we have called first order value outcomes as can be observed in Figure 1. These outcomes can be equally inferred in macro-level studies, however, the mechanisms by which they come about are not particularly well explained. These $1^{\text {st }}$ order value outcomes are the building blocks of higher order SC capability of (i) lean, a supply chain capability, (ii) agility, a first order SC dynamic capability, (iii) resilience, a second order SC dynamic capability, ultimately, a BDT-enabled SC has implication for the (iv) competitive advantage of a firm.

These value outcomes are however not mutually exclusive, indeed Dolgui et al. (2020) discuss the conceptual architecture of a reconfigurable supply chain network that celebrates the interaction between facets of digitalisation, lean, sustainability and resilience. Similarly, approaching supply chain management from an ecosystem perspective and framed against the backdrop of the COVID-19 pandemic, viability has been proposed as an integrating SC framework for resilience, agility, and sustainability (Ivanov and Dolgui, 2020a; Ivanov, 2020). Ivanov (2020, p. 1) describes such a viable supply chain (VSC) as "the ability of a supply chain to maintain itself and survive in a changing environment through a redesign of structures and replanning of performance with long-term impacts." In principle, a VSC model is tasked with 
matching supply and demand and to achieve this it draws on three feedback cycles of agility, resilience, and survivability (sustainability). The main challenge however is the establishment and control of adaptive mechanisms enabling the transitions between structural designs as dictated by the exigencies of supply and demand. The authors recognise the complexity of operating and controlling three SC designs simultaneously, the solution lies in prioritising the design and simulation of "virtual" supply chain structures for resilience and survivability while focussing on the adaptation trainings to practice the SC changeability. Here, the growing ubiquity of digital technologies, big data analytics and digital twin (Ivanov and Dolgui (2020b) in particular, is central to operationalising such a VSC model in practice.

Our own integrated framework shown in Figure 1 is built on empirical and quantitative evidence and shows the relationship between resilience, agility, and sustainability from a value perspective. It therefore provides an important platform to illuminate how practice and policy can benefit from research findings. Next, in a nod to practice and policy, we shine a spotlight on the evidence that explains how these value outcomes emerge, we then go on to share some thoughts on potential theoretical implications of our work.

\subsection{Practical and policy insights}

\subsubsection{BDT-enabled supply chain resilience}

The world has awoken to a new reality in COVID-19, this is characterized by significant contextual discontinuities in the operations and supply chain landscape, exposing serious frailties in existing practices. Business continuity has once again become the buzzword and the resilience of supply chains has commanded lively debates in the business and political worlds alike. A resilient supply chain has adaptive capability to manage global disruptions such as COVID-19, by enabling the supply chain to bend rather than to break. It is equipped with the capacity to overcome disruptions and continually transform itself to meet the changing needs 
and expectations of its customers, shareholders and other stakeholders (Pettit, 2008). According to Hohenstein et al. (2015, p. 108), supply chain resilience can be defined as:

The supply chain's ability to be prepared for unexpected risk events, responding and recovering quickly to potential disruptions to return to its original situation or grow by moving to a new, more desirable state in order to increase customer service, market share and financial performance.

Managing risks and developing resilience are two sides of the same coin (Hanke and Krumme, 2012). Indeed, the conceptual development of data-driven supply chain resilience systems point to the formation of cyber-physical risk analysis frameworks. One such frameworks is proposed by Ivanov and Dolgui (2020b), described as a digital twin (Dolgui et al., 2020; Panetto et al., 2019), it is a decision support system for disruption risk management based on data analytics and modelling employing real life information. In this arrangement, big data on historical disruption events is extracted and fed into a simulation model which employs information on the current supply chain design to stress-test the system. This helps managers understand how current system would perform under a particular risk event. Simulation is also run on alternative supply chain designs employing real-time data. This provides guidance on the optimal recovery policies for a particular risk event, information of which can be used to determine the performance impact of the disruptions and the key performance indicators (KPIs) affected.

Our study is timely in that it reveals myriads of potential applications where big data technologies could be leveraged to instill resilience in supply chains. Importantly, our findings show that publicly available data in the form of social media data could be a rich and potentially untapped repository of intelligence that could be deployed to build risk management capabilities in times of crisis. In micro-level studies, mathematical models that show how risk 
management capabilities could be developed are validated employing various sources of publicly available data. Wu and Barnes (2018) apply a mathematical model to social media data whereas Zhao et al. (2017) make use of financial data in a multi-objective optimization framework. For their part, Brintrup et al. (2019) model is validated using data from a manufacturer's Enterprise Resource Planning (ERP) system, whilst Chae et al., (2014a) apply a number of data analytics techniques to mine data from Twitter. The utility of big data to risk management has also been shown empirically with Zhan et al. (2016) finding big data to be a useful source of intelligence for mitigation of risk and market uncertainties in a longitudinal case study.

In terms of directly addressing resilience, Papadopoulos et al. (2017) make use of big data from different social media sources such as twitter, Facebook and YouTube to help reveal swift trust, quality information sharing and public-private partnerships as key enablers of resilience in a humanitarian supply chain. Here, policy makers could take some cues for future reference, particularly against the backdrop of the fiasco over the supply of personal protective equipment (PPE) in the United Kingdom (UK). Widely reported in the media, it is apparent that the supply chain for PPE was beset with a lack of trust and limited information sharing in the publicprivate partnerships spearheaded by the UK government, which did not bode well for its resilience and resulted in significant delays and failings. Prasad et al. (2016) also focus on the resilience of humanitarian supply chains and show how big data can help to create SC resilience through twelve longitudinal case studies. Others, such as Singh and Singh (2019) and Dubey et al. (2019b), employ surveys to establish a relationship between big data analytics (BDA) and supply chain resilience. 


\subsubsection{BDT-enabled supply chain agility}

Agility may be discussed in the same breath as resilience in the context of contextual discontinuities such as COVID-19. Indeed, supply chain agility is defined as the ability to quickly adjust the tactics and operations of the supply chain in responses to market changes (Naway and Rahmat, 2019). Christopher (2000) explains the criticality of accurate demand forecasting in creating agile responses. This is attributed to the structure of agile supply chains being linked significantly to manufacturing and logistics postponement strategies (Colin, 2006). According to Van Hoek, (2001), postponement is an organisational concept whereby some of the activities in the supply chain are not performed until customer orders are received. Where postponement strategies are used, the need for accurate demand forecasts as input to sales and operations planning is vital (Colin, 2006). Traditionally, single-point forecasts for key variables are used, however, these have been shown to provide inaccurate or completely wrong forecasts (Christopher and Holweg, 2011) particularly under conditions of uncertainty where the need for agility is critical. Hofmann (2017) concurs that traditional forecasting methods are often too rigid to react fast enough to unplanned supply chain events.

Evidence from micro-level studies shows how a big data-enabled approach to demand forecasting for supply chain agility can be achieved in practice. Hofmann (2017) explains how the three levers of velocity, variety and volume of big data could be simulated to model complex decision-making systems to combat bullwhip effect and in turn build up agility. Zhan et al. (2016) show that by leveraging customer demand identification capability optimised by BDT, firms can instil agility in the SC by responding to customers quickly and meeting their needs. For their part, Gunasekaran et al. (2018) demonstrate that companies are more likely to implement agile manufacturing enablers when big data technologies are effectively deployed to enhance demand planning processes including demand forecasting. Collectively, these findings provide some useful illustrations as the processes that can be optimised to achieve 
agility as well as the different types of data and analytics technologies that could be employed to achieve this.

\subsubsection{BDT-enabled formative elements of supply chain resilience and agility}

Resilience and agility are closely related concepts, both tend to describe a system's responsiveness to change (Sletbakk Ramstadet al., 2010). Attempts have been made to examine the similarities and differences between the two concepts with some arguing that although they have some elements in common, they reflect different origins and outcomes (Lengnick-Hall et al., 2011). Gölgeci et al. (2019) supply a more detailed analysis of the distinct features of the two concepts. They explain that while resistance and recovery are the central tenets of resilience, speed and acceleration characterise agility. As such, they associate resilience with longevity which does not necessarily imply prosperity, this is the preserve of agility. Further, resilience is viewed to be inward-looking while agility is considered to be typically outwardlooking. Perhaps the most contentious assertion, is the classification of resilience as reactionary compared to proactive agility. This is not a view that has universal acceptance, in fact, there are many examples of resilience as a reactive as well as a proactive form of response to change (e.g., Wieland and Wallenburg, 2013; Chowdhury and Quaddus, 2017; Elluru et al., 2019). We take the view shared by Christopher and Peck, (2004, p.13) that "resilience implies agility," indeed, empirical work has shown that improved resilience can be obtained by investing in agility (Weiland and Wallenburg, 2013). Overlaps between resilience and agility are also apparent in their formative elements. Much like resilience, agility is a multifaceted concept (Gölgeci et al., 2019). Speed and visibility have been suggested as the most salient aspects of agility in the supply chain context (Weiland and Wallenburg, 2013). To achieve agility, a firm needs visibility for a better identification of changes and speed for a faster response to changes (Christopher and Peck, 2004). Similarly, in the case of resilience, four facets of flexibility, 
speed, visibility and collaboration appear to be the most frequently mentioned, according to Jüttner and Maklan (2011) they seem to capture the conceptual essence of all suggestions.

Our analysis reveals some examples of how these formative elements may result from BDTenabled processes. At the micro-level, Blackburn et al., (2015) employ big data in the form of economic indicators and product prices in a statistical model to show how higher delivery capability and flexibility could be achieved with improved accuracy of demand forecasting. Sung et al. (2017) show how big data-enabled optimisation of assort-planning and distribution in the fashion retail industry can lead to improved flexibility in distribution. Enhanced demand forecasting has also been shown to impact on velocity by Choi (2016) who applies a mathematical proofing technique to social media comments related to fashion retailing. With regards to visibility, Singh et al., (2016) discuss how post launch product intelligence can be developed into market surveillance capability enabling timely recall of products (Mukherjee and Sinha, 2017). This enhanced visibility has the potential to instil agility in the return supply chain (Seuring, 2009).

In macro-level studies, Raman et al. (2018) demonstrate how Internet of things makes a significant contribution in providing real-time data visibility in supply chain management through big data analysis. Increased visibility may also result through BDT-enabled demand planning capabilities as shown by Schoenherr and Speier-Pero (2015). BDT has also been shown to have a positive impact on collaboration (Gunasekaran et al., 2018; Dubey et al.; 2019a) and responsiveness (Yu et al., 2018). Some micro-level studies have examined more than one of these formative elements. For example, Giannakis and Louis (2016) employ hypothetical scenarios in the context of product management to show how big data technologies can be leveraged to increase the speed, flexibility and responsiveness of new product development. In the case of Rajesh (2016), a grey prediction model is employed on a big data set from the Indian electronics industry to forecast measures of resilience and found 
flexibility, responsiveness and accessibility to be on the increase whereas quality and productivity showed slight decreases. Macro-level studies use different combinations of these formative elements in multi-item scales as measures of either operational (Chae et al. 2014a; Fosso-Wamba et al., 2019) or supply chain performance (Gawankar et al., 2019) to demonstrate the value creation potential of big data analytics capabilities in supply chains.

\subsubsection{BDT-enabled lean outcomes}

Lean is about doing more with less (Christopher, 2000). In the supply chain context lean is defined as a systematic approach to identify and eliminate waste through continuous improvement, flowing the product at the pull of the customer in pursuit of perfection (Kilpatrick, 2003; Sunder 2013). Lean is often contrasted with agile, as Christopher and Towill (2001) put it, the lean paradigm requires that "fat" be eliminated whereas the agile paradigm must be "nimble." According to Agarwal et al., (2006) a lean strategy could lead to profit maximisation through cost reduction while agility maximizes profit through providing exactly what the customer requires. Lean supply chains are normally associated with a day-to-day operational capability that stresses high level of efficiency in cost, quality and smooth operations flow (Yusuf et al., 2004). There is also a growing interest in the relationship between lean strategies and sustainable practices (Hartini and Ciptomulyono, 2015). This is reflected in the literature that shows that companies that adopt lean manufacturing strategies are more likely to adopt sustainability practices (Hassini, et al., 2012). For example, King and Lenox (2001) found strong support that lean leads to waste and pollution reduction. This support is further strengthened by Rothenberg et al. (2001) finding that lean production or just in time (JIT) can reduce emission of volatile organic compounds (VOCs) by leading to more efficient solvent use in paints. 
Our analysis reveals a variety of practical ways production systems may reap lean outcomes by implementing BDT to enhance SC processes. These outcomes include cost reduction $(\mathrm{f}=$ 14) and sustainability $(\mathrm{f}=10)$. Findings of micro-level studies are more revealing, illuminating those processes that when optimised by BDT could result in cost savings. Bock and Isik (2015) employ simulations to show how cost savings could be achieved by optimising order sizing. Blackburn et al. (2015) apply a mathematical model to economic data to show how demand forecasting for production planning could be enhanced leading to overall SC cost reduction. Employing data from an omni-channel marketing platform, Li et al. (2015) demonstrate how operational costs could be reduced through improved product tracking, marketing and channel management and product life-cycle management. For their part, Lamba et al. (2018) apply a mixed-integer nonlinear programming model to simulated big data to show how cost reductions could be achieved through optimised supplier selection process. Some macro-level studies employing survey methodology have also shown that the application of big data analytics in supply chains can have a positive effect on cost performance (e.g., Prasad et al., 2016; Schoenherr and Speier-Pero, 2015; Zhan et al., 2016; Fosso-Wamba et al., 2019; Dubey et al., 2019c; Srinivasan and Swink, 2018).

In terms of sustainability performance, this has been measured in micro-level studies as reduction in carbon dioxide $\left(\mathrm{CO}_{2}\right)$ and in macro-level studies as environmental performance. Our findings show how $\mathrm{CO}_{2}$ reduction in production systems may be achieved by applying BDT to optimise lot sizing (Kaur and Singh, 2018), supplier selection (Zhao et al., 2017; Lamba et al., 2018; Kaur and Singh, 2018; Singh et al., 2018) and carrier selection (Kaur and Singh, 2018). Opportunities to reduce $\mathrm{CO}_{2}$ has also been shown in transport design optimisation (How and Lam 2018) and in simulations (Doolun et al., 2018). Some macro-level studies have explained how big data analytics capabilities and environmental performance are linked (e.g., Dubey et al., 2017; Jeble et al., 2018; Raut et al., 2019; Singh and El-Kassar, 2019. Other 
studies explain how big data analytics could lead to efficient supply chain management (Raman et al., 2018; Schoenherr and Speier-Pero., 2015). Finally, the other lean outcomes captured by our analysis are quality (Fosso Wamba et al., 2019a) and reliability (Fernando et al., 2018). These are however not stand-alone measures, rather, they are constituents of multi-items operations performance measures.

\subsubsection{BDT-enabled firm performance}

Our findings show that ultimately, the application of big data technologies in supply chains causes value to manifest at the firm level. Studies, mostly macro-level, have measured these value outcomes directly or indirectly employing a variety of terminologies such as organisational performance (Gawankar et al., 2019), financial performance (Yu et al., 2018), firm performance (Fosso-Wamba and Akter, 2019) or economic performance (Jeble et al., 2018). Generally, these performance outcomes are represented by various combinations of financial metrics such as business growth (Chen et al., 2015), profit (Gunasekaran et al., 2018), and return on assets ( $\mathrm{Yu}$ et al., 2018) to name but a few. Other firm level value outcomes include customer satisfaction (Raman et al., 2018) and competitive advantage (Dubey et al., $2018,2019 b$ ) which is considered to be the highest order value outcome. While most relationships between big data analytics capabilities and firm level performance outcomes have been assessed directly, few interactions or indirect relationships have been examined. In FossoWamba and Akter (2019) the relationship between big data driven supply chain analytics and firm performance is mediated by supply chain agility whereas in Gawankar et al. (2019) the relationship between big data driven supply chain and organisational performance is mediated by supply chain performance. In terms of moderation, Dubey et al. (2018) found that organisational flexibility moderated the relationship between big data analytics capability and competitive advantage. Jeble et al. (2018), for their part, showed that supply base complexity 
moderated the relationship between big data and predictive capability and economic performance.

\subsection{Theoretical insights}

Our work contributes to the ongoing conversation on data-driven supply chain management. In this stream of literature, most empirical studies are operationalised by drawing on the resource-based theory or its sibling the dynamic capabilities lens. Consequently, studies have tended to operationalise big data technologies as a functional whole. As we have shown, it is difficult to comprehend and thus appreciate how big data technologies actually create value when these are treated as functional wholes. We have proposed the microfoundations of capabilities (Teece, 2007) as an alternative paradigm, we found that micro-founded studies are more nuanced and provide a more fine-grained understanding of the generative mechanisms of value in a BDT-enabled supply chain. In other words, the microfoundation approach allows supply chain capabilities to be analysed at a lower level of abstraction revealing the forces that are at play and how they interact to create value. However, most micro-founded studies in our sample employ a modelling-based methodology and generally do not engage with theory. This is an omission that we urge students of this scholarship to try and address as a matter of urgency.

As emergent capabilities, resilience and agility stand to benefit from a microfoundational approach. In the broader literature, scholars have struggled to unlock the black box that is resilience and agility. Operationalisation of these concepts has tended to downplay the generative mechanisms. Instead, these have often been conceptualised at the level of their formative elements, yet, guidance as to their building blocks are lacking. Through our findings we have revealed different ways in which those formative elements result from lower level interactions between supply chain processes and big data technologies. In essence, we have 
started to unlock the black box by revealing the generative mechanisms of resilience and agility. We therefore believe that we have taken the first step to illuminate the microfoundations of these important supply chain capabilities.

\section{Conclusion}

The pace with which big data technologies have settled in the supply chain management research stream is remarkable. The rate of publication in this area stands as testimony. However, in practice, the uptake of these technologies has not kept pace with the optimism expressed by commentators, speculators and even academics. We have sought to investigate why this might be the case in a bid to lift the mist on how BDT actually adds value to SCM. To do so we have examined the nature of the research evidence through a traditional content analysis of relevant high-quality published works. Our analysis has identified emerging trends and evaluated the potential added value of BDT to enhance the practice of SCM. Our study has shown that in the grand scheme of things micro-founded studies appear to be more illuminating to practice. In those studies, the crucial underlabourer's role of BDT in SCM is revealed.

The EQS literature is however not perfect and we have highlighted some of those imperfections. Nevertheless, at this final stage some key messages to practitioners and managers are worth iterating. The first take home message to managers and practitioners is that they should not ignore the value-added potential of BDT, they can be reassured by the detailed list of value-added activities that we have produced (Tables 12, 13). It is hard to imagine a future of SCM where big data do not play an increasing role in distinguishing between winners and losers. We have also exposed various useful sources of big data (Table 9) and these include social media as well as company databases. It is surprising that currently many firms do not have a comprehensive data management strategy (Iqbal et al., 2019). Our second take home message therefore impresses on managers to think very carefully about data in their operations 
and to identify the different sources of relevant data. The ultimate aim here is to promote the development of an organisational wide data management system. Managers can be encouraged by our findings that find utility in data from various sources. This information may also be leveraged to gain leadership and financial support for an organisational wide data management project.

Big data in and of themselves are of no value per se, the value resides in how these are transformed to generate intelligence and inform decision making. We have seen that this transformation is increasingly incumbent on knowledge of sophisticated mathematics and algorithms, therein lies our final take home message to managers and practitioners. Managers need to think creatively and strategically as to how to acquire the relevant skills-set in a highly prized market (Waller and Fawcett, 2013). Data science has been touted as a hot career choice and even sexy (Provost and Fawcett, 2013). Whilst the issue at hand may not necessarily involve building erotic capital (Hakim, 2010), nonetheless managers can use our findings as a nexus to understand the value data scientists can bring to their organisations and act strategically to procure their services. This will be particularly challenging for smaller firms without strong balance sheets, under these circumstances, managers may explore alternative modes of procurement such as outsourcing. To do noting however should not be considered an option, for ultimately, a firm's big data capability may be the single most important determinant factor between success and failure (Fruehauf et al., 2015).

\subsection{Limitations}

In our effort to present a review of the highest quality most studies in our sample are from ABS listed journals. Furthermore, we have excluded practitioner-based articles as well as conference papers. Inevitably, those quality related decisions have had an impact on the sample size and may have led to a narrow view of the field. Future review may consider how to include those 
outlets excluded in this review without compromising the quality and robustness of the process and findings.

\subsection{Implication for future research}

It is not our intention to level a charge of inappropriateness at certain methodological preferences, the evolution of any nascent research field stands to benefit from a broad church of approaches. Rather, irrespective of methodological choices, we contend that in order to unlock the black box of value creation in data driven supply chains and help to equip practitioners with the right kind of knowledge, more micro-founded studies are needed. The dynamic capabilities perspective offers the theoretical baggage to facilitate this future examination. However, given that dynamic capabilities result from lower level interactions we suggest the notion of microfoundation as an appropriate lens to help orchestrate the valuecreation generative dance between BDT and SCM.

There is also a significant imbalance between empirical and modelling methodologies. Whilst we do not wish to promote the stifling of the field, we feel that practitioners would benefit from more studies that are conceptualised to reflect the realities of day-to-day operations. As such, to redress the current imbalance we are advocating for more primary studies within this space. More specifically, longitudinal, in-depth case studies in organisations at the forefront of BDT adoption would serve to illuminate the intricacies of the BDT value creation dynamics in supply chains beyond what secondary research alone could reveal.

Knowledge creation in this field is also highly skewed reflecting a strong Anglo-American and Indo-Chinese dominance. We suspect that the mechanics of value creation might take a different dimension in still emerging and less developed regions given the differences that exist in terms of technological adoption between geographies. While high-income and mediumincome countries, such as those described above, are generally early adopters of technological 
innovations, low income countries typically in Africa, are generally laggards (Della Peruta, 2018). However, the speed of innovation is higher for low-income countries than for highincome countries benefiting from lower adoption costs, following a leader-follower model (Andrés et al., 2010). As such, the contrasting fortunes of low-income countries make for an interesting context to examine how the generative dance of value creation plays out. In return this may hasten the pace of adoption of such technologies potentially helping companies in those regions to compete on a global platform.

Whilst manufacturing and retailing sectors have been the early pacesetters in attracting more research interests, we believe that service industries ancillary to manufacturing and retailing, such as last mile logistics, offer great promises for researchers to make significant contributions. This is especially true as the notion of smart cities burgeons into an important contemporary research domain. Big data driven services (Hmoud et al., 2017), such as the big data-driven transportation system discussed in Mehmood et al., (2017) are likely to take centre stage in the smart cities context. Thus, we urge researchers to take up the challenge of BDT inspired services-related supply chain research with greater tenacity. In the context of the laggards discussed above, we see opportunities for empirical work in the area of BDT-enabled tourism supply chains in small island states.

Our findings show that demand management has been responsible for more value creation generative mechanisms compared to the other business processes of GSCF, suggesting a faster rate of maturation as a research domain. Further development of the field requires a more holistic understanding of how value can be created across all SC business processes. Practitioners stand to benefit from a more holistic understanding of the role of BDT in building supply chain capabilities. Our analysis has revealed agility as the most dominant higher order value instrument resulting from a BDT intervention. Supply chain resilience is a closely related capability and one that has gained significance importance due to its ability to mitigate against 
supply chain risks. We feel this is an important area deserving attention particularly as both the frequency and magnitude of risks faced by supply chains are also on the rise (Blackhurst et al., 2005).

Finally, our findings reveal a dominant process-based view of value creation in this stream of literature. This underplays the role of individuals in the process. A microfoundational approach to value-creation in a BDT-enabled SC requires that the human element is brought back in frame. Future studies that transcends different levels of conceptualisation are necessary not only to illuminate the roles of individuals but also to provide a more holistic understanding of the process of emergence from generative mechanisms to value outcomes in supply chains. 


\section{References}

ADDO-TENKORANG, R. \& HELO, P. T. 2016. Big data applications in operations/supply-chain management: A literature review. Computers and Industrial Engineering, 101, 528-543.

AGARWAL, A., SHANKAR, R. \& TIWARI, M. K. 2006. Modeling the metrics of lean, agile and leagile supply chain: An ANP-based approach. European Journal of Operational Research, 173, 211225.

AGHAEI CHADEGANI, A., SALEHI, H., MD YUNUS, M. M., FARHADI, H., FOOLADI, M., FARHADI, M. \& ALE EBRAHIM, N. 2013. A comparison between two main academic literature collections: Web of science and scopus databases. Asian Social Science, 9, 18-26.

AHMED, O., FATIMA-ZAHRA, B., AYOUB AIT, L. \& SAMIR, B. 2018. Big Data technologies: A survey. Journal of King Saud University: Computer and Information Sciences, 30, 431-448.

ANDERSSON, J. \& JONSSON, P. 2018. Big data in spare parts supply chains: The potential of using product-in-use data in aftermarket demand planning. International Journal of Physical Distribution and Logistics Management, 524-544.

ANDRÉS, L., CUBERES, D., DIOUF, M. \& SEREBRISKY, T. 2010. The diffusion of the Internet: A crosscountry analysis. Telecommunications Policy, 34, 323-340.

ARCHER, M. S. 1982. Morphogenesis versus Structuration: On Combining Structure and Action. The British Journal of Sociology, 33, 455-483.

ARUNACHALAM, D., KUMAR, N., KAWALEK, J. P. \& REVIEW, T. 2018. Understanding big data analytics capabilities in supply chain management: Unravelling the issues, challenges and implications for practice. Transportation Research Part E: Logistics, 114, 416-436.

ARYA, V., SHARMA, P., SINGH, A. \& DE SILVA, P. T. M. 2017. An exploratory study on supply chain analytics applied to spare parts supply chain. Benchmarking, 24, 1571-1580.

BABICEANU, R. F. \& SEKER, R. 2016. Big Data and virtualization for manufacturing cyber-physical systems: A survey of the current status and future outlook. Computers in Industry, 81, 128137.

BAILY, M., MANYIKA, J. \& GUPTA, S. 2013. U.S. Productivity Growth: An Optimistic Perspective. International Productivity Monitor 3-12.

BARBOSA, M. W., VICENTE, A. C., LADEIRA, M. B. \& DE OLIVEIRA, M. P. V. 2018. Managing supply chain resources with Big Data Analytics: a systematic review. International Journal of Logistics Research and Applications, 21, 177-200.

BARNEY, J. 1991. Firm Resources and Sustained Competitive Advantage. Journal of Management, 17, 99-120.

BARNEY, J. \& FELIN, T. 2013. What are microfoundations? The Academy of Management perspectives: $A M P, 27,138-155$.

BARNEY, J. B. 1997. Gaining and sustaining competitive advantage, Reading, Massachusetts, Addison-Wesley.

BLACKBURN, R., LURZ, K., PRIESE, B., GÖB, R. \& DARKOW, I. L. 2015. A predictive analytics approach for demand forecasting in the process industry. International Transactions in Operational Research, 22, 407-428.

BLACKHURST, J., CRAIGHEAD, C. W., ELKINS, D. \& HANDFIELD, R. B. 2005. An empirically derived agenda of critical research issues for managing supply-chain disruptions. International Journal of Production Research, 43, 4067-4081.

BOCK, S. \& ISIK, F. 2015. A new two-dimensional performance measure in purchase order sizing. International Journal of Production Research, 53, 4951-4962.

BRINCH, M., STENTOFT, J., JENSEN, J. K. \& RAJKUMAR, C. 2018. Practitioners understanding of big data and its applications in supply chain management. The International Journal of Logistics Management, 29, 555-574. 
BRINTRUP, A., PAK, J., RATINEY, D., PEARCE, T., WICHMANN, P., WOODALL, P. \& MCFARLANE, D. 2019. Supply chain data analytics for predicting supplier disruptions: a case study in complex asset manufacturing. International Journal of Production Research, 1-12.

CHAE, B., YANG, C., OLSON, D. \& SHEU, C. 2014a. The impact of advanced analytics and data accuracy on operational performance: A contingent resource based theory (RBT) perspective. Decision Support Systems, 59, 119-126.

CHAE, B. K., OLSON, D. \& SHEU, C. 2014b. The impact of supply chain analytics on operational performance: A resource-based view. International Journal of Production Research, 52, 4695-4710.

CHAVEZ, R., YU, W., JACOBS, M. A. \& FENG, M. 2017. Data-driven supply chains, manufacturing capability and customer satisfaction. Production Planning and Control, 28, 906-918.

CHEN, C. P. \& ZHANG, C.-Y. 2014. Data-intensive applications, challenges, techniques and technologies: A survey on Big Data. Information sciences, 275, 314-347.

CHEN, D. Q., PRESTON, D. S. \& SWINK, M. 2015a. How the Use of Big Data Analytics Affects Value Creation in Supply Chain Management. Journal of Management Information Systems, 32, 439.

CHEN, J. S., KERR, D., TSANG, S. S. \& SUNG, Y. C. 2015b. Co-production of service innovations through dynamic capability enhancement. Service Industries Journal, 35, 96-114.

CHEN, Y. J. \& CHIEN, C. F. 2018. An empirical study of demand forecasting of non-volatile memory for smart production of semiconductor manufacturing. International Journal of Production Research, 1-15.

CHOI, T. M. 2016. Incorporating social media observations and bounded rationality into fashion quick response supply chains in the big data era. Transportation Research Part E: Logistics and Transportation Review.

CHOI, T. M., WALLACE, S. W. \& WANG, Y. 2018. Big Data Analytics in Operations Management. Production and Operations Management, 27, 1868-1883.

CHOWDHURY, M. M. H. \& QUADDUS, M. 2017. Supply chain resilience: Conceptualization and scale development using dynamic capability theory. International Journal of Production Economics, 188, 185-204.

CHRISTOPHER, M. 2000. The Agile Supply Chain: Competing in Volatile Markets. Industrial Marketing Management, 29, 37-44.

CHRISTOPHER, M. \& HOLWEG, M. 2017. Supply chain 2.0 revisited: a framework for managing volatility-induced risk in the supply chain. International Journal of Physical Distribution and Logistics Management, 47, 2-17.

CHRISTOPHER, M. \& PECK, H. 2004. Building the Resilient Supply Chain. The International Journal of Logistics Management, 15, 1-14.

CHRISTOPHER, M. \& TOWILL, D. 2001. An integrated model for the design of agile supply chains. International Journal of Physical Distribution \& Logistics Management, 31, 235-246.

COLLIN, J. \& LORENZIN, D. 2006. Plan for supply chain agility at Nokia: Lessons from the mobile infrastructure industry. International Journal of Physical Distribution \& Logistics Management, 36, 418-430.

COLLIS, D. 1994. RESEARCH NOTE - HOW VALUABLE ARE ORGANIZATIONAL CAPABILITIES. Strategic Management Journal, 15, 143-152.

COOPER, M. C., LAMBERT, D. M. \& PAGH, J. D. 1997. Supply chain management: more than a new name for logistics. The international journal of logistics management, 8, 1-14.

DELLA PERUTA, M. 2018. Adoption of mobile money and financial inclusion: a macroeconomic approach through cluster analysis. Economics of Innovation and New Technology, 27, 154173.

DOLGUI, A., IVANOV, D. \& SOKOLOV, B. 2020. Reconfigurable supply chain: the X-network. International Journal of Production Research, 58, 4138-4163. 
DOOLUN, I. S., PONNAMBALAM, S. G., SUBRAMANIAN, N. \& G, K. 2018. Data driven hybrid evolutionary analytical approach for multi objective location allocation decisions: Automotive green supply chain empirical evidence. Computers and Operations Research.

DRNEVICH, P. L. \& KRIAUCIUNAS, A. P. 2011. Clarifying the conditions and limits of the contributions of ordinary and dynamic capabilities to relative firm performance. Strategic Management Journal, 32, 254-279.

DUBEY, R., GUNASEKARAN, A., CHILDE, S., WAMBA, S. \& PAPADOPOULOS, T. 2016. The impact of big data on world-class sustainable manufacturing. The International Journal of Advanced Manufacturing Technology, 84, 631-645.

DUBEY, R., GUNASEKARAN, A. \& CHILDE, S. J. 2018. Big data analytics capability in supply chain agility: The moderating effect of organizational flexibility. Management Decision.

DUBEY, R., GUNASEKARAN, A., CHILDE, S. J., BLOME, C. \& PAPADOPOULOS, T. 2019a. Big Data and Predictive Analytics and Manufacturing Performance: Integrating Institutional Theory, Resource - Based View and Big Data Culture. British Journal of Management, 30, 341-361.

DUBEY, R., GUNASEKARAN, A., CHILDE, S. J., FOSSO WAMBA, S., ROUBAUD, D. \& FOROPON, C. 2019b. Empirical investigation of data analytics capability and organizational flexibility as complements to supply chain resilience. International Journal of Production Research, 1-19.

DUBEY, R., GUNASEKARAN, A., CHILDE, S. J., PAPADOPOULOS, T., LUO, Z., WAMBA, S. F. \& ROUBAUD, D. 2017. Can big data and predictive analytics improve social and environmental sustainability? Technological Forecasting and Social Change.

DUBEY, R., GUNASEKARAN, A., CHILDE, S. J., ROUBAUD, D., FOSSO WAMBA, S., GIANNAKIS, M. \& FOROPON, C. 2019c. Big data analytics and organizational culture as complements to swift trust and collaborative performance in the humanitarian supply chain. International Journal of Production Economics, 210, 120-136.

EASTON, G., GILCHRIST, A. \& LENNEY, P. The Co-constitutiveness Nature of Organizations and Industrial Networks: A Critical Realist Approach'. 28th IMP Conference, 2012. 1-24.

EISENHARDT, K. M. \& MARTIN, J. A. 2000. Dynamic capabilities: what are they? Strategic management journal, 21, 1105-1121.

EKSTRÖM, T. \& SELVIARIDIS, K. Performance based contracting capabilities-A pre-study of Swedish defence acquisition. Proceedings of the 31st International Symposium on Military Operating Research, Department of Industrial Management and Logistics, Lund University, London, UK, 2014.

ELLIS, S. C., RAO, S., RAJU, D. \& GOLDSBY, T. J. 2018. RFID Tag Performance: Linking the Laboratory to the Field through Unsupervised Learning. Production and Operations Management, 27, 1834-1848.

ELLRAM, L. M., TATE, W. L. \& BILLINGTON, C. 2004. Understanding and Managing the Services Supply Chain. Journal of Supply Chain Management, 40, 17-32.

ELLURU, S., GUPTA, H., KAUR, H. \& SINGH, S. P. 2019. Proactive and reactive models for disaster resilient supply chain. Annals of Operations Research, 283, 199-224.

FAHIMNIA, B., TANG, C. S., DAVARZANI, H. \& SARKIS, J. 2015. Quantitative models for managing supply chain risks: A review. European Journal of Operational Research, 247, 1-15.

FAWCETT, S. E. \& WALLER, M. A. 2014. Supply chain game changers-mega, nano, and virtual trendsand forces that impede supply chain design (i.e., Building a Winning Team). Journal of Business Logistics, 35, 157-164.

FELDMAN, M. S. 2003. A performative perspective on stability and change in organizational routines. Industrial and corporate change, 12, 727-752.

FELIN, T. \& FOSS, N. J. 2005. Strategic organization: a field in search of micro-foundations. Strategic Organization, 3, 441-455.

FERNANDO, Y., CHIDAMBARAM, R. R. M. \& WAHYUNI-TD, I. S. 2018. The impact of Big Data analytics and data security practices on service supply chain performance. Benchmarking: An International Journal, 25, 4009-4034. 
FOLINAS, D., MANTHOU, V., SIGALA, M. \& VLACHOPOULOU, M. 2004. E-volution of a supply chain: cases and best practices. Internet Research, 14, 274-283.

FOSS, N. J. \& PEDERSEN, T. 2016. Microfoundations in Strategy Research. Strategic Management Journal, 37, 22-34.

FOSSO-WAMBA, S., DUBEY, R., GUNASEKARAN, A. \& AKTER, S. 2019. The performance effects of big data analytics and supply chain ambidexterity: The moderating effect of environmental dynamism. International Journal of Production Economics, 107498.

FOSSO WAMBA, S. \& AKTER, S. 2019. Understanding supply chain analytics capabilities and agility for data-rich environments. International Journal of Operations \& Production Management, 39, 887-912.

FOSSO WAMBA, S., AKTER, S., EDWARDS, A., CHOPIN, G. \& GNANZOU, D. 2015. How 'big data' can make big impact: Findings from a systematic review and a longitudinal case study. International Journal of Production Economics, 165, 234-246.

FOSSO WAMBA, S., EDWARDS, A. D. \& SHARMA, R. 'Big Data' as a strategic enabler of superior emergency service management: lessons from the New South Wales state emergency service. ICIS 2012 MIS Quarterly Executive Workshop, 2012.

FREEMAN, R. E. 1984. Strategic management: a stakeholder approach, Boston, Pitman.

FRUEHAUF, J., AL-KHALIFA, F. \& CONIKER, J. 2015. Using the bolman and deal's four frames in developing a data governance strategy. Issues in Information Systems, 16.

GAWANKAR, S. A., GUNASEKARAN, A. \& KAMBLE, S. 2019. A study on investments in the big datadriven supply chain, performance measures and organisational performance in Indian retail 4.0 context. International Journal of Production Research, 58, 1574-1593.

GIANNAKIS, M. \& LOUIS, M. 2016. A multi-agent based system with big data processing for enhanced supply chain agility. Journal of Enterprise Information Management, 29, 706-727.

GOLD, S. \& SEURING, S. 2011. Supply chain and logistics issues of bio-energy production. Journal of Cleaner Production, 19, 32-42.

GÖLGECI, I., ARSLAN, A., DIKOVA, D. \& GLIGOR DAVID, M. 2019. Resilient agility in volatile economies: institutional and organizational antecedents. Journal of Organizational Change Management, 33, 100-113.

GRANT, R. M. 1991. The Resource-Based Theory of Competitive Advantage: Implications for Strategy Formulation. California Management Review, 33, 114-135.

GRAY, M., SHARLAND, E., HEINSCH, M. \& SCHUBERT, L. 2015. Connecting research to action: Perspectives on research utilisation. The British Journal of Social Work, 45, 1952-1967.

GREAN, M. \& SHAW, M. J. 2002. Supply-chain partnership between P\&G and Wal-Mart. E-Business Management. Springer.

GUNASEKARAN, A., PAPADOPOULOS, T., DUBEY, R., WAMBA, S. F., CHILDE, S. J., HAZEN, B. \& AKTER, S. 2017. Big data and predictive analytics for supply chain and organizational performance. Journal of Business Research, 70, 308-317.

GUNASEKARAN, A., YUSUF, Y. Y., ADELEYE, E. O. \& PAPADOPOULOS, T. 2018. Agile manufacturing practices: the role of big data and business analytics with multiple case studies. International Journal of Production Research, 56, 385-397.

GUPTA, S., ALTAY, N. \& LUO, Z. 2017. Big data in humanitarian supply chain management: a review and further research directions. Annals of Operations Research, 1-21.

GUTHRIE, J. \& ABEYSEKERA, I. 2006. Content analysis of social, environmental reporting: what is new? Journal of Human Resource Costing \& Accounting, 10, 114-126.

GUTHRIE, J. \& MATHEWS, M. R. 1985. Corporate social accounting in Australasia. Research in corporate social performance and policy. JAI Press.

HAKIM, C. 2010. Erotic capital. European Sociological Review, 26, 499-518.

HANKE, T. \& KRUMME, K. 2012. Risk and resilience in sustainable supply chain managementconceptual outlines. 
HARTINI, S. \& CIPTOMULYONO, U. 2015. The Relationship between Lean and Sustainable Manufacturing on Performance: Literature Review. Procedia Manufacturing, 4, 38-45.

HARVEY, C., KELLY, A., MORRIS, H. AND ROWLINSON, M 2010. The Association of Business Schools. Academic Journal Quality Guide, 4.

HASSINI, E., SURTI, C. \& SEARCY, C. 2012. A literature review and a case study of sustainable supply chains with a focus on metrics. International Journal of Production Economics, 140, 69-82.

HMOUD, A. Y., SALIM, J. \& YAAKUB, M. R. 2017. A Two-Sided Market Mechanisms Toward Designing a Big Data-Driven Business Model for Mobile Network Operators (MNOs). Journal of Telecommunication, Electronic and Computer Engineering, 9, 105-110.

HOFMANN, E. 2017. Big data and supply chain decisions: the impact of volume, variety and velocity properties on the bullwhip effect. International Journal of Production Research, 55, 51085126.

HOHENSTEIN, N.-O., FEISEL, E., HARTMANN, E. \& GIUNIPERO, L. 2015. Research on the phenomenon of supply chain resilience: A systematic review and paths for further investigation. International Journal of Physical Distribution \& Logistics Management, 45, 90-117.

HOW, B. S. \& LAM, H. L. 2018. Sustainability evaluation for biomass supply chain synthesis: Novel principal component analysis (PCA) aided optimisation approach. Journal of Cleaner Production, 189, 941-961.

HU, H., WEN, Y., CHUA, T. S. \& LI, X. 2014. Toward scalable systems for big data analytics: A technology tutorial. IEEE Access, 2, 652-687.

HUANG, G. Q., ZHONG, R. Y. \& TSUI, K. L. 2015. Special issue on 'big data for service and manufacturing supply chain management'. International Journal of Production Economics, $165,172-173$.

IQBAL, R., YUDA, P., ADITYA, W., HIDAYANTO, A. N., HANDAYANI, P. W. \& HARAHAP, N. C. Master Data Management Maturity Assessment: Case Study of XYZ Company. 2019 2nd International Conference on Applied Information Technology and Innovation (ICAITI), 2019. IEEE, 133-139.

IVANOV, D. 2020. Viable supply chain model: integrating agility, resilience and sustainability perspectives-lessons from and thinking beyond the COVID-19 pandemic. Annals of Operations Research.

IVANOV, D. \& DOLGUI, A. 2020a. Viability of intertwined supply networks: extending the supply chain resilience angles towards survivability. A position paper motivated by COVID-19 outbreak. International Journal of Production Research, 58, 2904-2915.

IVANOV, D. \& DOLGUI, A. 2020b. A digital supply chain twin for managing the disruption risks and resilience in the era of Industry 4.0. Production Planning \& Control, 1-14.

JEBLE, S., DUBEY, R., CHILDE, S. J., PAPADOPOULOS, T., ROUBAUD, D. \& PRAKASH, A. 2018. Impact of big data and predictive analytics capability on supply chain sustainability. The International Journal of Logistics Management, 29, 513-538.

JÜTTNER, U. \& MAKLAN, S. 2011. Supply chain resilience in the global financial crisis: An empirical study. Supply Chain Management, 16, 246-259.

KAHI, V. S., YOUSEFI, S., SHABANPOUR, H. \& SAEN, R. F. 2017. How to evaluate sustainability of supply chains? A dynamic network DEA approach. Industrial Management and Data Systems, 117, 1866-1889.

KAUR, H. \& SINGH, S. P. 2018. Heuristic modeling for sustainable procurement and logistics in a supply chain using big data. Computers and Operations Research, 98, 301-321.

KILPATRICK, J. 2003. Lean principles. Utah Manufacturing Extension Partnership, 68, 1-5.

KIM, M.-C., KIM, C. O., HONG, S. R. \& KWON, I.-H. 2008. Forward-backward analysis of RFID-enabled supply chain using fuzzy cognitive map and genetic algorithm. Expert Systems With Applications, 35, 1166-1176. 
KING, A. \& LENOX, M. 2001. Lean and Green? An Empirical Examination of the Relationship Between Lean Production and Environmental Performance. Production and Operations Management, 10, 244-256.

KOLBE, R. \& BURNETT, M. 1991. Content-Analysis Research: An Examination of Applications with Directives for Improving Research Reliability and Objectivity. Journal of Consumer Research, $18,243-250$.

KUMAR, M., GRAHAM, G., HENNELLY, P. \& SRAI, J. 2016. How will smart city production systems transform supply chain design: a product-level investigation. International Journal of Production Research, 54, 7181-7192.

LAMBA, K. \& SINGH, S. P. 2017. Big data in operations and supply chain management: current trends and future perspectives. Production Planning and Control, 28, 877-890.

LAMBA, K., SINGH, S. P. \& MISHRA, N. 2018. Integrated decisions for supplier selection and lot-sizing considering different carbon emission regulations in Big Data environment. Computers and Industrial Engineering.

LAMBERT, D. M. \& COOPER, M. C. 2000. Issues in Supply Chain Management. Industrial Marketing Management, 29, 65-83.

LENGNICK-HALL, C. A., BECK, T. E. \& LENGNICK-HALL, M. L. 2011. Developing a capacity for organizational resilience through strategic human resource management. Human Resource Management Review, 21, 243-255.

LEONARD-BARTON, D. 1992. Core capabilities and core rigidities: A paradox in managing new product development. Strategic Management Journal, 13, 111-125.

LI, Q., LUO, H., XIE, P. X., FENG, X. Q. \& DU, R. Y. 2015. Product whole life-cycle and omni-channels data convergence oriented enterprise networks integration in a sensing environment. Computers in Industry, 70, 23-45.

LIGHT, R. J. \& PILLEMER, D. B. 1984. Summing up: the science of reviewing research, Cambridge, Mass Harvard University Press.

MAHADEVAN, B. 2000. Business Models for Internet-Based E-Commerce: An Anatomy. California Management Review, 42, 55-69.

MANYIKA, J., LUND, S., BUGHIN, J., WOETZEL, J. R., STAMENOV, K. \& DHINGRA, D. 2016. Digital globalization: The new era of global flows, McKinsey Global Institute San Francisco.

MATTHIAS, O., FOUWEATHER, I., GREGORY, I. \& VERNON, A. 2017. Making sense of Big Data - can it transform operations management? International Journal of Operations \& Production Management, 37, 37-55.

MCAFEE, A., BRYNJOLFSSON, E., DAVENPORT, T. H., PATIL, D. \& BARTON, D. J. H. B. R. 2012. Big data: the management revolution. Harvard business review, 90, 60-68.

MEHMOOD, R., MERITON, R., GRAHAM, G., HENNELLY, P. \& KUMAR, M. 2017. Exploring the influence of big data on city transport operations: a Markovian approach. International Journal of Operations and Production Management, 37, 75-104.

MELNYK, S. A., LUMMUS, R. R., VOKURKA, R. J., BURNS, L. J. \& SANDOR, J. 2009. Mapping the future of supply chain management: a Delphi study. International Journal of Production Research, 47, 4629-4653.

MENTZER, J. T., DEWITT, W., KEEBLER, J. S., MIN, S., NIX, N. W., SMITH, C. D. \& ZACHARIA, Z. G. 2001. Defining supply chain management. Journal of Business Logistics, 22, 1-25.

MERITON, R. F. \& PANDZA, K. 2015. The morphogenesis of organisational capabilities. Strategic Management Society. Denver, Collorado US.

MIKALEF, P., FRAMNES, V. A., DANIELSEN, F., KROGSTIE, J. \& OLSEN, D. Big Data Analytics Capability: Antecedents and Business Value. PACIS, 2017. 136.

MINGERS, J. \& HARZING, A.-W. 2007. Ranking journals in business and management: a statistical analysis of the Harzing data set. European Journal of Information Systems, 16, 303-316. 
MOKTADIR, M. A., ALI, S. M., PAUL, S. K. \& SHUKLA, N. 2018. Barriers to big data analytics in manufacturing supply chains: A case study from Bangladesh. Computers and Industrial Engineering.

MOODY, D. Building links between IS research and professional practice: improving the relevance and impact of IS research. ICIS Proceedings, 2000. 31-32.

MUKHERJEE, U. K. \& SINHA, K. K. 2017. Product Recall Decisions in Medical Device Supply Chains: A Big Data Analytic Approach to Evaluating Judgment Bias. Production and Operations Management.

MUSA, A. \& DABO, A.-A. 2016. A Review of RFID in Supply Chain Management: 2000-2015. Global Journal of Flexible Systems Management, 17, 189-228.

NAWAY, F. A. \& RAHMAT, A. 2019. The mediating role of technology and logistic integration in the relationship between supply chain capability and supply chain operational performance. Uncertain Supply Chain Management, 7, 553-566.

NEWBERT, S. L. 2007. Empirical research on the resource - based view of the firm: an assessment and suggestions for future research. Strategic Management Journal, 28, 121-146.

NGUYEN, T., ZHOU, L., SPIEGLER, V., IEROMONACHOU, P. \& LIN, Y. 2017. Big data analytics in supply chain management: A state-of-the-art literature review. Computers and Operations Research.

NIGHTINGALE, A. 2009. A guide to systematic literature reviews. Surgery (Oxford), 27, 381-384.

OUSSOUS, A., BENJELLOUN, F.-Z., LAHCEN, A. A. \& BELFKIH, S. 2018. Big Data technologies: A survey. Journal of King Saud University-Computer Information Sciences, 30, 431-448.

PANDZA, K., POLAJNAR, A., BUCHMEISTER, B. \& THORPE, R. 2003. Evolutionary perspectives on the capability accumulation process. International Journal of Operations \& Production Management, 23, 822-849.

PANETTO, H., IUNG, B., IVANOV, D., WEICHHART, G. \& WANG, X. 2019. Challenges for the cyberphysical manufacturing enterprises of the future. Annual Reviews in Control, 47, 200-213.

PAPADOPOULOS, T., GUNASEKARAN, A., DUBEY, R., ALTAY, N., CHILDE, S. J. \& FOSSO-WAMBA, S. 2017. The role of Big Data in explaining disaster resilience in supply chains for sustainability. Journal of Cleaner Production, 142, 1108-1118.

PENROSE, E. T. 1959. The theory of the growth of the firm, Oxford, Basil Blackwell.

PETERAF, M. 1993. The Cornerstones of Competitive Advantage: A Resource-based View. Strategic Management Journal, 14, 179.

PETTIT, T. 2008. Supply Chain Resilience: Development of a Conceptual Framework, an Assessment Tool and an Implementation Process. The Ohio State University.

PFEFFER, J. \& SALANCIK, G. R. 1978. The external control of organizations: a resource dependence perspective, New York, Harper \& Row.

PRASAD, S., ZAKARIA, R. \& ALTAY, N. 2016. Big data in humanitarian supply chain networks: a resource dependence perspective. Annals of Operations Research, 1-31.

PROVOST, F. \& FAWCETT, T. 2013. Data science and its relationship to big data and data-driven decision making. Big data, 1, 51-59.

QUINCI, C. 2015. Defining and developing translation competence for didactic purposes: Some insights from product-oriented research. Handbook of Research on Teaching Methods in Language Translation and Interpretation. IGI Global.

RAI, A., PATNAYAKUNI, R. \& SETH, N. 2006. Firm performance impacts of digitally enabled supply chain integration capabilities. MIS Quarterly, 30, 225-246.

RAJESH, R. 2016. Forecasting supply chain resilience performance using grey prediction. Electronic Commerce Research and Applications, 20, 42-58.

RAMAN, S., PATWA, N., NIRANJAN, I., RANJAN, U., MOORTHY, K. \& MEHTA, A. 2018. Impact of big data on supply chain management. International Journal of Logistics Research and Applications, 1-18. 
RAUT, R. D., MANGLA, S. K., NARWANE, V. S., GARDAS, B. B., PRIYADARSHINEE, P. \& NARKHEDE, B. E. 2019. Linking big data analytics and operational sustainability practices for sustainable business management. Journal of Cleaner Production, 224, 10-24.

REW, D. 2010. SCOPUS: Another step towards seamless integration of the world's medical literature. European Journal of Surgical Oncology, 36, 2-3.

RICHEY, R. G., MORGAN, T. R., LINDSEY-HALL, K. \& ADAMS, F. G. 2016. A global exploration of Big Data in the supply chain. International Journal of Physical Distribution \& Logistics Management, 46, 710-739.

RODEN, S., NUCCIARELLI, A., LI, F. \& GRAHAM, G. 2017. Big data and the transformation of operations models: a framework and a new research agenda. Production Planning \& Control: Big data and analytics in operations and supply chain management: managerial aspects and practical challenges, 28, 929-944.

ROßMANN, B., CANZANIELLO, A., VON DER GRACHT, H. \& HARTMANN, E. 2018. The future and social impact of Big Data Analytics in Supply Chain Management: Results from a Delphi study. Technological Forecasting and Social Change, 130, 135-149.

ROTHENBERG, S., PIL, F. K. \& MAXWELL, J. 2001. Lean, green, and the quest for superior environmental performance. Production and Operations Management, 10, 228-243.

ROWLEY, J. \& SLACK, F. 2004. Conducting a literature review. Management Research News, 27, 3139.

RUSSOM, P. 2011. Big data analytics. TDWI best practices report, fourth quarter, 19, 1-34.

SALTZ, J. S. \& SHAMSHURIN, I. 2016. Big data team process methodologies: A literature review and the identification of key factors for a project's success. IEEE International Conference on Big Data.

SANDERS, N. R. 2016. How to use big data to drive your supply chain. California Management Review, 58, 26-48.

SAUNDERS, M., LEWIS, P. AND THORNHILL, A 2007. Research Methods for Business Students, Edinburgh Gate, Harlow, Financial Times Prentice Hall.

SCHOENHERR, T. \& SPEIER-PERO, C. 2015. Data science, predictive analytics, and big data in supply chain management: Current state and future potential. Journal of Business Logistics, 36, 120132.

SCHREYÖGG, G. \& KLIESCH - EBERL, M. 2007. How dynamic can organizational capabilities be? Towards a dual - process model of capability dynamization. Strategic Management Journal, 28, 913-933.

SEURING, S. 2009. The product-relationship-matrix as framework for strategic supply chain design based on operations theory. International Journal of Production Economics, 120, 221-232.

SEURING, S. \& MÜLLER, M. 2008. From a literature review to a conceptual framework for sustainable supply chain management. Journal of Cleaner Production, 16, 1699-1710.

SINGH, A., KUMARI, S., MALEKPOOR, H. \& MISHRA, N. 2018. Big data cloud computing framework for low carbon supplier selection in the beef supply chain. Journal of Cleaner Production, 202, 139-149.

SINGH, A., SHUKLA, N. \& MISHRA, N. 2016. Social media data analytics to improve supply chain management in food industries. Transportation Research Part E: Logistics and Transportation Review.

SINGH NITYA, P. \& SINGH, S. 2019. Building supply chain risk resilience: Role of big data analytics in supply chain disruption mitigation. Benchmarking: An International Journal, 26, 2318-2342.

SINGH, S. K. \& EL-KASSAR, A.-N. 2019. Role of big data analytics in developing sustainable capabilities. Journal of Cleaner Production, 213, 1264-1273.

SLACK, N., LEWIS, M. \& BATES, H. 2004. The two worlds of operations management research and practice. International Journal of Operations \& Production Management, 24, 372-387. 
SLETBAKK RAMSTAD, L., HALVORSEN, K. \& WAHL, A. M. 2010. Improved Coordination with Integrated Planning: Organisational Capabilities. SPE Intelligent Energy Conference and Exhibition. Utrecht, The Netherlands: Society of Petroleum Engineers.

SONI, G. \& KODALI, R. 2012. A critical review of empirical research methodology in supply chain management. Journal of Manufacturing Technology Management, 23, 753-779.

SOUZA, G. C. 2014. Supply chain analytics. Business Horizons, 57, 595-605.

SRINIVASAN, R. \& SWINK, M. 2018. An Investigation of Visibility and Flexibility as Complements to Supply Chain Analytics: An Organizational Information Processing Theory Perspective. Production and Operations Management, 27, 1849-1867.

STOCK, JR. \& BOYER, S. 2009. Developing a consensus definition of supply chain management: a qualitative study. International Journal Of Physical Distribution \& Logistics Management, 39, 690-711.

SUNDER, M. V. 2013. Synergies of lean six sigma. IUP Journal of Operations Management, 12, 21-31.

SUNG, S. W., JANG, Y. J., KIM, J. H. \& LEE, J. 2017. Business analytics for streamlined assort packing and distribution of fashion goods at kolon sport. Interfaces, 47, 555-573.

TAN, K. H., ZHAN, Y., JI, G., YE, F. \& CHANG, C. 2015. Harvesting big data to enhance supply chain innovation capabilities: An analytic infrastructure based on deduction graph. International Journal of Production Economics, 165, 223-233.

TEECE, D. J. 2007. Explicating dynamic capabilities: the nature and microfoundations of (sustainable) enterprise performance. Strategic Management Journal, 28, 1319-1350.

TEECE, D. J., PISANO, G. \& SHUEN, A. 1997. Dynamic capabilities and strategic management. Strategic Management Journal, 18, 509-533.

TRANFIELD, D., DENYER, D. \& SMART, P. 2003. Towards a Methodology for Developing Evidence Informed Management Knowledge by Means of Systematic Review. British Journal of Management, 14, 207-222.

TSAI, C.-W., LAI, C.-F., CHAO, H.-C. \& VASILAKOS, A. V. 2015. Big data analytics: a survey. Journal of Big data, 2, 2-21.

UDAGAWA, M. 1995. The Development of Production Management at the Toyota Motor Corporation. Business History, 37, 107-119.

UNHELKAR, B. 2017. Big Data Strategies for Agile Business, CRC Press.

VALLET-BELLMUNT, T., MARTÍNEZ-FERNÁNDEZ, M. T. \& CAPÓ-VICEDO, J. 2011. Supply chain management: A multidisciplinary content analysis of vertical relations between companies, 1997-2006. Industrial Marketing Management, 40, 1347-1367.

VAN DER SPOEL, S., AMRIT, C. \& VAN HILLEGERSBERG, J. 2017. Predictive analytics for truck arrival time estimation: a field study at a European distribution centre. International Journal of Production Research, 55, 5062-5078.

VAN HOEK, R. I. 2001. The rediscovery of postponement a literature review and directions for research. Journal of Operations Management, 19, 161-184.

VERMA, C., PANDEY, R. \& KATIYAR, D. 2018. Performance Evaluating System Based on MapReduce in Context of Educational Big Data. International Journal of Organizational Collective Intelligence, 8, 1-12.

WAINWRIGHT, D., OATES, B., EDWARDS, H. \& CHILDS, S. 2018. Evidence-Based Information Systems: A New Perspective and a Road Map for Research-Informed Practice. Journal of the Association for Information Systems, 19, 1035-1063.

WALLER, M. A. \& FAWCETT, S. E. 2013. Data science, predictive analytics, and big data: A revolution that will transform supply chain design and management. Journal of Business Logistics, 34, 77-84.

WANG, C. L. \& AHMED, P. K. 2007. Dynamic capabilities: A review and research agenda. International Journal of Management Reviews, 9, 31-51. 
WANG, G., GUNASEKARAN, A., NGAI, E. W. T. \& PAPADOPOULOS, T. 2016a. Big data analytics in logistics and supply chain management: Certain investigations for research and applications. International Journal of Production Economics, 176, 98-110.

WIELAND, A., HANDFIELD, R. B. \& DURACH, C. F. 2016. Mapping the Landscape of Future Research Themes in Supply Chain Management. Journal of Business Logistics, 37, 205-212.

WIELAND, A. \& MARCUS WALLENBURG, C. 2013. The influence of relational competencies on supply chain resilience: a relational view. International Journal of Physical Distribution \& Logistics Management, 43, 300-320.

WINTER, S. G. 2003. Understanding dynamic capabilities. Strategic Management Journal, 24, 991995.

WU, C. \& BARNES, D. 2018. Design of agile supply chains including the trade-off between number of partners and reliability. The International Journal of Advanced Manufacturing Technology, 97, 3683-3700.

WU, S. J., MELNYK, S. A. \& FLYNN, B. B. 2010. Operational Capabilities: The Secret Ingredient. Decision Sciences, 41, 721-754.

YEH, Y.-P. 2005. Identification of factors affecting continuity of cooperative electronic supply chain relationships: empirical case of the Taiwanese motor industry. Supply Chain Management: An International Journal, 10, 327-335.

YU, L., ZHAO, Y., TANG, L. \& YANG, Z. 2018. Online big data-driven oil consumption forecasting with Google trends. International Journal of Forecasting.

YU, W. 2015. The effect of IT-enabled supply chain integration on performance. Production Planning \& Control, 26, 945-957.

YUSUF, Y., GUNASEKARAN, A., ADELEYE, E. O. \& SIVAYOGANATHAN, K. 2004. Agile supply chain capabilities: Determinants of competitive objectives. European Journal Of Operational Research, 159, 379-392.

ZAHRA, S. \& GEORGE, G. 2002. Absorptive capacity: a review, reconceptualization, and extension. Academy of Management review, 27, 185-203.

ZAKI, M., THEODOULIDIS, B., SHAPIRA, P., NEELY, A. \& TEPEL, M. F. 2019. Redistributed Manufacturing and the Impact of Big Data: A Consumer Goods Perspective. Production Planning \& Control: Redistributed Manufacturing - Challenges for Operations Management, 30, 568-581.

ZHAN, Y., TAN, K. H., LI, Y. \& TSE, Y. K. 2016. Unlocking the power of big data in new product development. Annals of Operations Research, 1-19.

ZHAO, R., LIU, Y., ZHANG, N. \& HUANG, T. 2017. An optimization model for green supply chain management by using a big data analytic approach. Journal of Cleaner Production, 142, 1085-1097. 